\title{
Structural and Electrochemical Properties of Physisorbed and
}

\section{Chemisorbed Water Layers on the Ceramic Oxides $\mathrm{Y}_{2} \mathrm{O}_{3}, \mathrm{YSZ}$ and $\mathrm{ZrO}_{2}$}

Eva-Maria Köck ${ }^{1}$, Michaela Kogler ${ }^{1}$, Bernhard Klötzer ${ }^{1}$, Michael F. Noisternig ${ }^{2}$, Simon Penner $^{1, *}$

${ }^{1}$ Institute of Physical Chemistry, University of Innsbruck, Innrain 80-82, A-6020 Innsbruck

${ }^{2}$ Institute of Pharmaceutical Technology, University of Innsbruck, Innrain 52c, A-6020 Innsbruck, Austria

Keywords: water adsorption, dynamic moisture sorption, FT-IR spectroscopy, electrochemical impedance spectroscopy, charge carrier activation, bulk and surface conductivity, grain boundary conductivity, electrolyte resistance, polarization resistance

*Corresponding author: $\quad$ simon.penner@uibk.ac.at, $\quad$ Tel: 004351250758003 , Fax: 004351250758198 


\section{Abstract}

The present study focuses on the adsorption and conduction behavior of $\mathrm{H}_{2} \mathrm{O}$ and $\mathrm{D}_{2} \mathrm{O}$ on the technologically important ceramic oxides $\mathrm{YSZ}\left(8 \mathrm{~mol} \% \mathrm{Y}_{2} \mathrm{O}_{3}\right), \mathrm{ZrO}_{2}$ and $\mathrm{Y}_{2} \mathrm{O}_{3}$. For YSZ, a sequential dissociative water - "ice-like" layer - polymeric chained water - "liquid-like" water adsorption model for isothermal and isobaric conditions over a pressure range of $10^{-5}$ mbar up to 24 mbar and a temperature range from room temperature up to $1173 \mathrm{~K}$ could be established and experimentally verified, using a combination of operando Fourier-Transform infrared spectroscopy, operando electrochemical impedance spectroscopy and moisture sorption measurements. In contrast to highly hydroxylated $\mathrm{YSZ}$ and $\mathrm{Y}_{2} \mathrm{O}_{3}$, a high surface concentration of $\mathrm{OH}$ groups from water chemisorption is absent on pure monoclinic $\mathrm{ZrO}_{2}$ at any temperature/pressure and thus, the ice-like and following molecular water layers exhibit no measurable protonic conduction. The characteristic changes of the related infrared bands could directly be linked to the associated conductivity and moisture sorption data. As the characterization of the chemisorbed and physisorbed water layers are imperative to a full understanding of (electro-)catalytically active doped oxide surfaces and their application in technology, the presented data provide the specific reactivity of these oxides towards water over a pressure/temperature parameter range extending up to e.g. solid-oxide fuel cell (SOFC)-relevant conditions. In due course, we show that the water layers even under these rather extreme experimental conditions play a key role in understanding the function of these materials. Furthermore, the reported data are supposed to provide an extended basis for further investigation of close-to-real gas adsorption or catalyzed heterogeneous reactions. 


\section{Introduction}

Water chemistry on catalysts plays a key role in every efficient process ${ }^{1-5}$, emphasized by the fact that a certain amount of mostly surface-bound water is always present in technical processes, e.g. upon energy generation in fuel cells. The amount of hydroxylation and even the amount of physisorbed water molecules on especially the oxide support of metal-oxide composite materials plays an important role for the overall activity of the system. ${ }^{1}$ The actual contribution of $\mathrm{OH}$-groups or other water-derived adsorbates on support and metal particle is currently an increasingly and intensively studied question, ${ }^{6}$ as catalytic water activation on oxides in general is a cornerstone in catalyzed reactions like reforming reactions, the water gas shift reaction (WGSR) ${ }^{7}$ or in water-assisted CO oxidation. ${ }^{8-10}$ In this respect, water is an active participant of the catalytic reaction, either as a reactant or as a co-catalyst, and crucially influences e.g. the $\mathrm{CO}_{2}$ selectivity in methanol or methane steam reforming reactions. ${ }^{11,12}$ Understanding the activation processes of adsorbed water molecules on different structural sites is thereby imperative. Besides a pure "catalytic" role, the adsorbed water molecules can also indirectly influence the material's properties. An instructive example is the well-known improvement of (especially surface) conduction processes by adsorbed water layers. ${ }^{13,14}$ In fact, for a range of mainly ceramic oxides, including $\mathrm{Y}_{2} \mathrm{O}_{3}, \mathrm{ZrO}_{2}$ or $\mathrm{Y}_{2} \mathrm{O}_{3}$-doped $\mathrm{ZrO}_{2}$, the "reduction" process in hydrogen has been basically shown to be limited to the surface layers and, thus, to the reversible removal of surface hydroxyl groups. ${ }^{14}$ Naturally, this behavior is strongly dependent on the quality and quantity of the adsorbed water layers (i.e. if physisorption or chemisorption prevails) and the chemical nature of the adsorbing surface sites. Most importantly, these adsorbed water layers might also play a crucial role under comparably harsh experimental conditions (e.g. high temperatures) of relevant technological processes, where adsorbed water at first sight appears unlikely. A well-known example are solid-oxide fuel cells (SOFC's), to which fuel reforming or reformate mixtures (e.g. moist syngas) are fed. ${ }^{15}$ However, despite the importance of understanding the role of the chemistry 
and stability of these water layers stable at high temperatures and pressures, information in this respect is scarce. To eventually fill this knowledge gap, three representative "real" powder ceramic oxide materials with potential technological relevance have been chosen to directly highlight the water adsorption features as a function of surface chemistry. $\mathrm{Y}_{2} \mathrm{O}_{3}, \mathrm{ZrO}_{2}$ and YSZ (stabilized by $8 \mathrm{~mol} \% \mathrm{Y}_{2} \mathrm{O}_{3}$ ) have therefore been selected, partly also because a large body of data of adsorption and material properties already exists, ranging from $\mathrm{CO}$ and $\mathrm{CO}_{2}$ adsorption to reduction in $\mathrm{CO}$ or hydrogen. ${ }^{16-19}$

By combining operando Fourier-Transform infrared measurements, operando electrochemical impedance spectroscopy and dynamic moisture sorption investigations at different water partial pressures and temperatures it is, thus, possible to directly link the changes in surface chemistry caused by water adsorption to changes in the electrochemical behavior. In this respect, the resulting electrochemical response towards $\mathrm{H}_{2} \mathrm{O}$ and $\mathrm{D}_{2} \mathrm{O}$ at the respective application-oriented conditions, including isothermal and isobaric studies on pressed polycrystalline powder samples with water pressures between $10^{-5}$ mbar and ambient pressure, as well as a temperature range from room temperature up to $1173 \mathrm{~K}$ is studied. The pure oxides are thus investigated to clearly determine the contribution of the "isolated" oxidic components without the influence of metal particles and metal-oxide interfacial zones, which is increasingly necessary in order to disentangle the individual features of catalyst systems or complex materials in general. As a final note, more details of the structure of the adsorbed water layers on oxides have been jointly provided as an introductory chapter in the Results and Discussion section.

\section{Experimental}

\subsection{Materials}

Commercial powders of $\mathrm{Y}_{2} \mathrm{O}_{3}$ (yttrium(III) oxide, $<50 \mathrm{~nm}$ particle size, Sigma-Aldrich), $\mathrm{ZrO}_{2}$ (zirconium(IV) oxide, 99.978\%, Alfa Aesar), and YSZ (zirconium(IV)oxide, nanopowder, containing $8 \mathrm{~mol} \% \mathrm{Y}_{2} \mathrm{O}_{3}$ as stabilizer, Sigma Aldrich) were used as starting 
materials. All samples were pre-treated by calcination at $1173 \mathrm{~K}$ in air and checked by XRD for structural changes upon annealing. To assure the same starting conditions and to guarantee that all samples are equally sintered for electrochemical impedance and Fourier-Transform infrared spectroscopy, the samples were heated in pure oxygen up to $1273 \mathrm{~K}$ with an extended isothermal period for $1 \mathrm{~h}$ before each experiment inside the respective setup. The surface areas after the pre-treatments were determined by BET nitrogen adsorption at $77 \mathrm{~K}$ (Quantachrome Nova 2000 Surface Area and Pore Size Analyzer) as $120 \mathrm{~m}^{2} \mathrm{~g}^{-1}\left(\mathrm{Y}_{2} \mathrm{O}_{3}\right), 32$ $\mathrm{m}^{2} \mathrm{~g}^{-1}$ (YSZ), and $2 \mathrm{~m}^{2} \mathrm{~g}^{-1}\left(\mathrm{ZrO}_{2}\right)$. Gases were supplied by Messer $\left(\mathrm{O}_{2} 3.5\right.$, He 5.0). The cooling trap temperature was $\sim 153 \mathrm{~K}$ for $\mathrm{O}_{2}$. $\mathrm{D}_{2} \mathrm{O}$ was purchased from Sigma Aldrich (Deuterium oxide, 99.9 at.- \% D).

\subsection{FT-IR spectroscopy}

FT-IR spectra were recorded in transmission mode on an Agilent Cary 660 spectrometer with a mid-infrared source and a DTGS detector. The powder samples were pressed into thin pellets using a pressure equivalent to $2 \mathrm{t}$ on a $0.8 \mathrm{~cm}^{2}$ area (sample diameter $10 \mathrm{~mm}$, mass about $20 \mathrm{mg}$ ) and then subsequently placed inside a home-made operando reactor cell. ${ }^{20}$ This cell provides an absolutely inert surrounding of the sample in the heated area. In situ/operando measurements up to $1273 \mathrm{~K}$ under flowing and static conditions can be performed. Vacuum conditions at a minimum pressure of $3 \cdot 10^{-7} \mathrm{mbar}$ are possible. The window material $\mathrm{BaF}_{2}$ allows access to wavelengths above $800 \mathrm{~cm}^{-1}$. Experiments in flowing mode can be directly correlated with electrochemical impedance measurements and are performed using He as carrier gas. In static mode, water vapor can be added stepwise into the evacuated cell and is desorbed from a water reservoir that was degassed to remove dissolved $\mathrm{CO}_{2}$. All reported spectra are corrected by the spectrum of the dry pre-oxidized oxide pellet at room temperature and under vacuum prior to exposure to water.

\subsection{Electrochemical impedance spectroscopy}


The in situ/operando impedance cell consists of an outer quartz tube with two inner quartz tubes to which the sample and the electrodes are attached. Heating was provided by a tubular Linn furnace and controlled by a thermocouple (K-element), located in the reactor about 5 mm downstream of the sample, and a Micromega PID temperature controller. The impedance was measured by an IM6e impedance spectrometer (Zahner Messsysteme), which provides data on the impedance and the phase angle of the current as a function of voltage. The powder samples were pressed into pellets with a pressure equivalent to $2 \mathrm{t}$ on a $0.2 \mathrm{~cm}^{2}$ area (sample diameter $5 \mathrm{~mm}$, mass about $20 \mathrm{mg}$ ) and placed between two circular Pt electrodes forming a plate capacitor in mechanically enforced contact with the sample pellet.

For all temperature-programmed impedance measurements described in this article, an amplitude of $20 \mathrm{mV}$ of the superimposed sinusoidal modulation voltage signal at an overall DC potential of $0 \mathrm{~V}$ and a frequency of $1 \mathrm{~Hz}$ were applied to the Pt electrodes, i.e. the impedance of the pellet was effectively measured in an electrochemically unpolarized state. In all temperature-dependent experiments the impedance modulus $|Z|$, obtained at $1 \mathrm{~Hz}$ modulation frequency, will be further referred to as "impedance".

Water vapor of 24 mbar was introduced by passing $\mathrm{He}\left(1 \mathrm{~mL} \mathrm{~s}^{-1}\right)$ through a water saturator at room temperature. For establishing a partial pressure of 4 mbar, the sublimation pressure of ice Ih was established, using a $\mathrm{LN}_{2} / \mathrm{EtOH}$ cooling trap at $\sim 270 \mathrm{~K} .{ }^{21}$ For the re-oxidation after moist treatments a $\mathrm{LN}_{2} / \mathrm{EtOH}$ cooling trap at $\sim 153 \mathrm{~K}$ was used.

Nyquist plots are obtained isothermally at a given temperature in a frequency range between $100 \mathrm{mHz}$ and $0.1 \mathrm{MHz}$ at the same amplitude of the superimposed sinusoidal voltage signal that is also used for the temperature-dependent impedance measurements. The real and imaginary part of the impedance are first measured from $1 \mathrm{kHz}$ up to $0.1 \mathrm{MHz}$ (within $14 \mathrm{~s}$ ) and then from $0.1 \mathrm{MHz}$ down to $100 \mathrm{mHz}$ (within $4 \mathrm{~m} 24 \mathrm{~s}$; total measuring time: $4 \mathrm{~m} 38 \mathrm{~s}$ ) to check for time-dependent changes of the system during EIS. The obtained data have been fitted with the equivalent circuit model shown in Figure 9. 
Arrhenius analysis was performed to determine the activation energies for certain temperature regions. From the temperature dependent EIS measurements the conductivity was calculated by taking the reciprocal of the impedance modulus value and plotting $\ln$ (conductivity) vs. the reciprocal of the reaction temperature. This conductivity is proportional to the sum of the total charge carrier concentration and not specific for a certain kind of charge carrier. Hence, in the more frequent cases of mixed charge carrier conductance, an "apparent" activation energy can be determined. This calculated activation energy is usually the weighted sum of several contributions, that is, if several activated processes occur simultaneously with unknown relative contributions, it may be possible only in exceptional cases to refer one specific $\mathrm{E}_{\mathrm{A}}$ to a single charge transport process. Thus, we are able to identify qualitative changes in the $\mathrm{E}_{\mathrm{A}}$ being clearly related to changes on the surface. The resistance values obtained from the fit of the Nyquist plots for the different processes were also transformed into conductivities. As in the case of the temperature dependent EIS measurements, "apparent" activation energies were calculated.

\subsection{Sorption measurements}

The dynamic moisture sorption experiments over a relative humidity (r.h.) range of $0 \%$ to $95 \%$, at $25.0{ }^{\circ} \mathrm{C}$, were measured on an automated multi-sample moisture sorption analyzer (SPS11, ProUmid GmbH \& Co. KG), equipped with an analytical balance (Mettler Toledo $\mathrm{GmbH})$ of $10 \mu \mathrm{g}$ resolution. The processed dry air flow has an effective minimum partial water pressure/minimum relative humidity of $1 \%$.

The samples $(0.04 \mathrm{~g}$ to $0.5 \mathrm{~g})$ were placed in aluminium dishes and loaded in the instrument, where the sample mass change was recorded in 10 minutes interval over a total period of 18.5 days. The measurement cycles are programmed in steps (in \% r.h.): 40-30-20-10-5-0-5-10-2030-40-50-60-70-80-90-95-90-80-70-60-50-40-30-20-10-5-0-5-10-20-30-40. The minimum time per step was 300 minutes and the maximum time was set to 48 hours. Once the samples reached the equilibrium condition ( $0.003 \%$ mass change within 60 minutes), the next step was 
started automatically. Due to the dynamic atmosphere in the chamber and the fluffy powder state of $\mathrm{Y}_{2} \mathrm{O}_{3}$, all sample pans and the reference pan were covered with a lightweight sieve.

\section{Results and Discussion}

\subsection{General remarks on the state of literature}

Before discussing our results on $\mathrm{YSZ}, \mathrm{ZrO}_{2}$ and $\mathrm{Y}_{2} \mathrm{O}_{3}$, a brief summary of the actual state in literature is provided to establish a basic concept for a comparable discussion of water adsorption on different oxides.

As water adsorption is a very complex field of knowledge, a vast bulk of literature exists including UHV studies, theoretical investigations and ambient pressure experiments on a huge variety of characterized adsorber materials like any kind of metals, oxides, salts or composites. Two comprehensive reviews concerning water adsorption available, one from Thiel and Madey ${ }^{22}$ (1987) and from Henderson ${ }^{6}$ (2002) exist. The latter gives a very detailed insight into possible structures and reactions of water with many metals, but also some oxide surfaces. Henderson roughly distinguishes between UHV and non-UHV conditions, which are divided into so called 'high-pressure' studies and liquid-solid interfacial studies. In the UHV community, the term 'high pressure' is referred to pressures below $10^{-6}$ mbar. Derived from Thiel et. al. and Henderson et. al., in general, clustering of water molecules is a wide-spread phenomenon, both under UHV conditions and at higher pressures. With increasing water coverage several distinguishable binding states of water can be identified. Henderson suggests three categories of adsorbed water from an energetic viewpoint: (i) the case of a much stronger water-surface interaction than water-water interaction (often leads to dissociation); (ii) a similar or equal water-surface to water-water interaction (first few water layer(s)) and (iii) water layers where the surface-water interaction plays a minor part. Figure 1 visualizes this generalized concept of distinguishable water 'layers'. Concerning category (i), especially on defective or chemically suitable surfaces water can dissociate and form surface OH-groups with usually two types of $\mathrm{OH}$-groups present: terminal (“t”- $\mathrm{OH}$, just one bond from the 
oxygen atom to the surface) and multi-coordinated ("m"-OH, two or even more bonds to the surface) hydroxyl groups. The dissociation processes already take place under UHV conditions. The initial formation or the general presence of hydroxyl groups enhances further adsorption of water due to favored binding of water molecules via hydrogen bonds. The first "physisorbed" water layer (category (ii)) and, depending on the substrate, also a few more layers, respectively, are structurally "ice-like" (i.e. restricted in terms of molecular degrees of freedom) due to the "pinning" influence of the surface. This ice-like water layer is bonded extremely strongly (although it is "only" molecularly adsorbed = physisorbed) and shows totally different adsorption kinetics and conduction mechanisms compared to the layers above. Depending on the surface, adsorption of the ice-like layer takes place under non-UHV conditions. Applying even higher pressure, more physisorbed water layers are present (category (iii)). These water molecules with a greater distance to the surface tend to be less structured and also diffusion of H-atoms (Grotthuss mechanism, proton hopping between randomly adsorbed water molecules ${ }^{13}$ ) becomes more likely, which in literature is often referred to as "polymeric chained" or "poly-nuclear"23 water due to the typical network of structured hydrogen bonds in this layer.

An example, which is in good correlation with the concept in Figure 1, is the structural composition of water clusters on $\mathrm{TiO}_{2}{ }^{24}$. The authors claim that every water molecule can form four hydrogen bonds at maximum - two as hydrogen bond acceptor ( $\mathrm{O}$ atom) and two as hydrogen bond donor ( $\mathrm{H}$ atom). The number of intermolecular hydrogen bonds consequently strongly influences the electronic/binding state of the molecule, especially if the regarding water molecule acts as a hydrogen donor. The main part of water molecules in the "bulk" of the cluster can be viewed as polymeric chained $\mathrm{H}_{2} \mathrm{O}$ molecules. In contrast, the outside spherical part of a "free" cluster is formed by water molecules with their $\mathrm{H}$ atoms outside of the cluster, leading to a weaker influence of hydrogen bonding to its chemical state. The first (ice-like) water layer on the surface of the oxide is again set apart insofar as the water 
molecules are only hydrogen-bonded to the upper layers with their electronic state being also strongly influenced by the bond to the oxide surface. The presence of chemisorbed hydroxyl groups does also strongly influence the binding of the first physisorbed water layer.

At water pressures near the saturation vapor pressure of water, an additional category of adsorbed water (comparable with condensation) should be defined: a from now on called "liquid-like" phase, where diffusion of whole water molecules is possible (Figure 1).

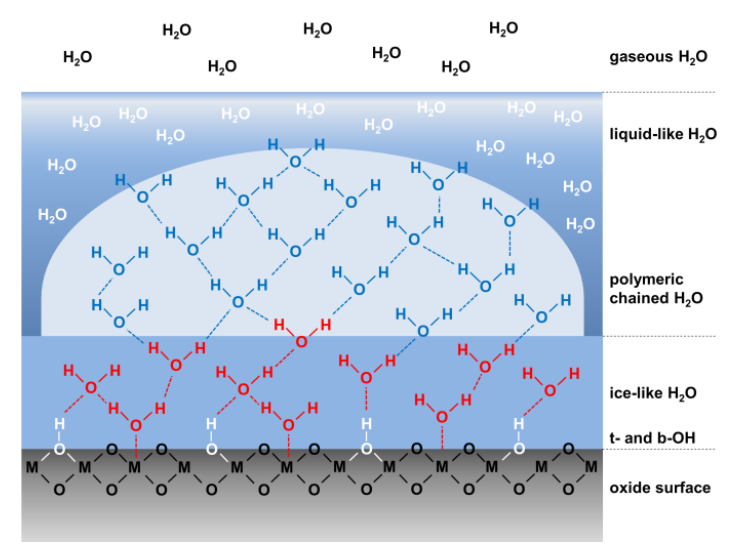

Figure 1: Generalized structural concept of water adsorption on an oxide surface.

In this study, especially with respect to the general energetic concept of water adsorption, FTIR, dynamic moisture sorption and EIS measurements on $\mathrm{ZrO}_{2}$, YSZ and $\mathrm{Y}_{2} \mathrm{O}_{3}$ were performed. The data are subsequently critically discussed in how far the quite generalized concept in Figure 1 is adaptable to the investigated oxides. Thus, to give the reader a better context, the aim of the experiments will be discussed in the beginning of each further section. Except from the structural properties of the adsorbed water, the status of the adsorbing substrate should also be discussed critically. The major part in literature providing detailed structure information of adsorbed water and forming the major focus in the Henderson review is single crystals. Oxides, especially in powder form, are rarely investigated, with the exception of $\mathrm{TiO}_{2}, \mathrm{SiO}_{2}$ and $\mathrm{MgO}$. Details about water adsorption/hydroxylation on $\mathrm{ZrO}_{2}$ are summarized in a review by Kouva et. al. ${ }^{23}$. The core point of the latter is that not only the total amount of hydroxylation but also the chemical nature of the hydroxyl groups are extremely 
dependent on the pre-treatment of the oxide. Also the molecular adsorption of water concerning amount and binding properties - is drastically dependent on the pre-treatment. The crucial parameter is the temperature, directly related with surface area, defect sites, particle size or predominant crystalline surfaces. Thus, also the concentration of dissociation or other binding sites, $\mathrm{OH}$-concentration and type of $\mathrm{OH}$ groups are affected.

In our case the oxides are used as pressed powder samples (pre-)treated under SOFC relevant conditions (i.e. temperatures up to $1273 \mathrm{~K}$ ). Upon comparing a single crystal with a powder sample there are additional parameters to consider. In general, the conducted measurements are based on comparably large-scale analytical techniques gathering data of the whole sample surface. As the surface area depends on several parameters of the oxides' pre-treatment, the samples were exclusively pre-treated in $\mathrm{LN}_{2} / \mathrm{EtOH}$ dried $\mathrm{O}_{2}$ up to $1273 \mathrm{~K}$ leading to controlled sample annealing and sintering, suppressing a high amount of remaining defects. The resulting "fixed" specific surfaces represent a realistic structurally invariant state, being the actual state of the oxides after pre-sintering under realistic conditions. We are aware of the fact that the surface of $\mathrm{ZrO}_{2}\left(2 \mathrm{~m}^{2} \mathrm{~g}^{-1}\right)$ is much lower than the ones of YSZ $\left(32 \mathrm{~m}^{2} \mathrm{~g}^{-1}\right)$ and $\mathrm{Y}_{2} \mathrm{O}_{3}\left(120 \mathrm{~m}^{2} \mathrm{~g}^{-1}\right)$. Polycrystalline powder samples might also offer structurally distinct adsorption sites (certain distribution of terminal crystallographic planes, under-coordinated sites at corners and edges, lattice dislocations, stacking faults or grain boundaries), which are absent on well-defined single crystals.

The adsorption of $\mathrm{D}_{2} \mathrm{O}$ was additionally comparatively studied to $\mathrm{H}_{2} \mathrm{O}$ adsorption since $\mathrm{H} / \mathrm{D}$ exchange is a common method to clarify reaction mechanisms/kinetics ${ }^{23}$ and the $\mathrm{D}_{2} \mathrm{O}$-related differences in adsorption properties or conduction effects provide valuable additional information.

\subsection{FT-IR spectroscopy}

As for isothermal experiments the lowest applied pressure is $10^{-5}$ mbar and the samples are pre-treated in dry $\mathrm{O}_{2}\left(\mathrm{LN}_{2} / \mathrm{EtOH}\right.$ trap) up to $1273 \mathrm{~K}$, the surface starting state most likely 
already provides a certain amount of hydroxylation (maximum of chemisorption on the annealed surface) and at maximum, very few physisorbed water molecules. The pressure of water vapor can be exactly controlled between $10^{-3}$ mbar and 24 mbar. Thus, it is possible to evaluate the water uptake starting from the ice-like layer up to the increasing amount of polymeric chained water layers. The highest applied water vapor pressure is 24 mbar (saturation vapor pressure of water at room temperature), which creates a multilayer watercovered surface up to liquid-like layers of water. With this setup, the energetic binding strength and correlated order of the water molecules in the different previously defined adsorption categories is directly expressed by the vibrational band of the respective $\mathrm{O}-\mathrm{H}$ bond.

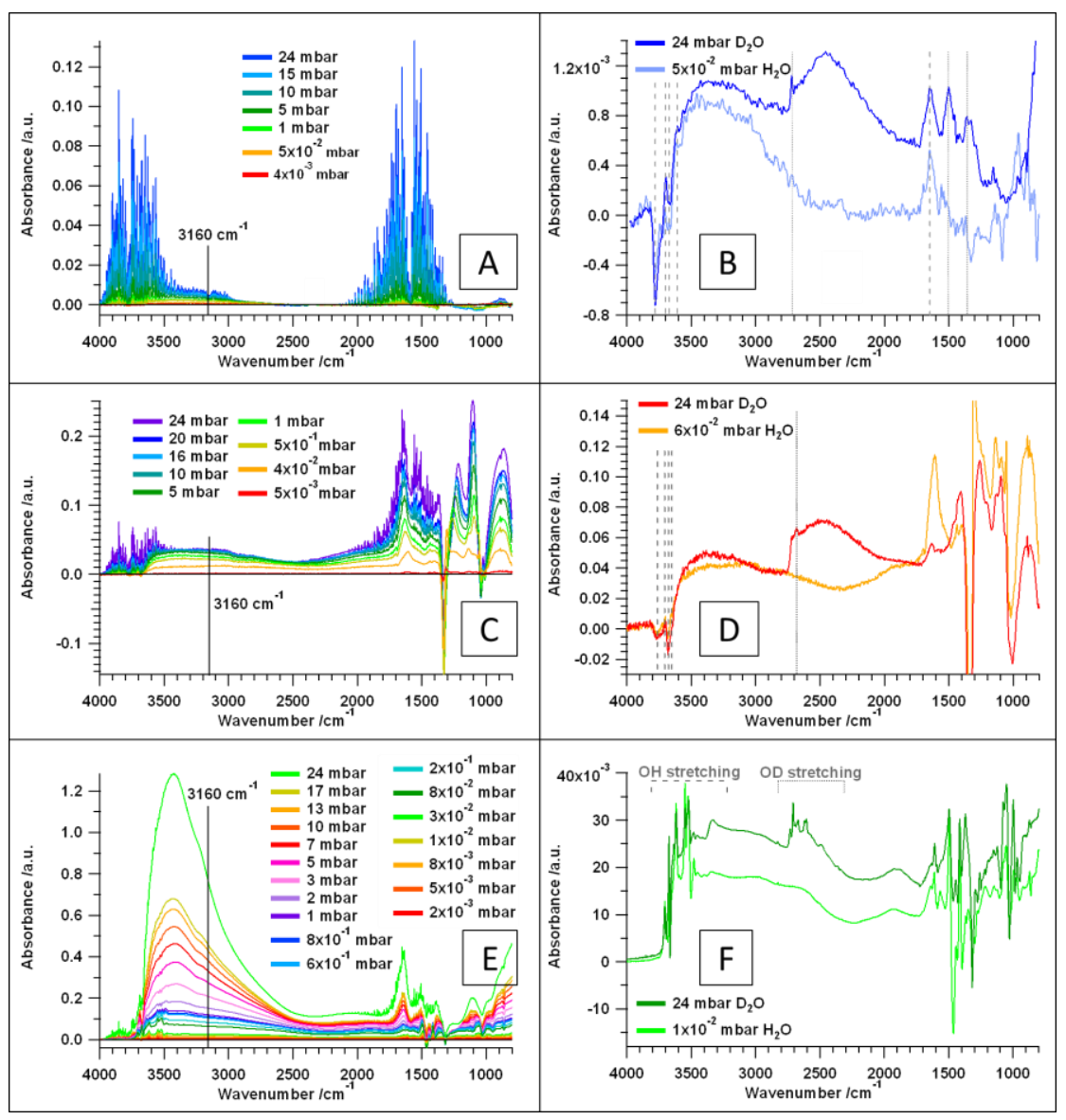

Figure 2: Isothermal FT-IR measurements of $\mathrm{ZrO}_{2}(\mathrm{~A})$ and (B), YSZ (C) and (D) and $\mathrm{Y}_{2} \mathrm{O}_{3}$ (E) and (F). (A), (C) and (E): experiments in pure $\mathrm{H}_{2} \mathrm{O}$ vapor pressures from $\sim 10^{-3}$ mbar up to 
24 mbar at room temperature; (B), (D) and (F): comparison of $\sim 24$ mbar $\mathrm{D}_{2} \mathrm{O}$ vapor and $\sim 10^{-2}$ mbar $\mathrm{H}_{2} \mathrm{O}$ vapor.

Figure 2 shows an overview of the different water pressures on (A) $\mathrm{ZrO}_{2}$, (B) YSZ and (C) $\mathrm{Y}_{2} \mathrm{O}_{3}$. On $\mathrm{ZrO}_{2}$, signals for gaseous water are predominant at low pressures and the signals for adsorbed water are largely obscured by the strong $\mathrm{H}_{2} \mathrm{O}(\mathrm{g})$ bands. A definitive interpretation is possible at pressures below $1 \cdot 10^{-1}$ mbar, where the signals for gas phase water are not screening the bands of adsorbed water. A spectrum of $\mathrm{ZrO}_{2}$ in $5 \cdot 10^{-2} \mathrm{mbar} \mathrm{H}_{2} \mathrm{O}$ is displayed in Figure $2 \mathrm{~B}$ in comparison to a spectrum of $\mathrm{ZrO}_{2}$ in 24 mbar $\mathrm{D}_{2} \mathrm{O}$. The first distinct differences are two negative peaks at $3780 \mathrm{~cm}^{-1}$ and $3670 \mathrm{~cm}^{-1}$. As a negative peak in a ratio spectrum indicates the change of a feature of the sample that was saved with the background spectrum, a change can be an actual removal/reaction of the regarding feature or just a change in the bond-length changing the position of the infrared band. The above mentioned negative signals are typical for the $\mathrm{t}-\mathrm{OH}\left(3780 \mathrm{~cm}^{-1}\right)$ and $\mathrm{m}-\mathrm{OH}\left(3670 \mathrm{~cm}^{-1}\right)$ groups of monoclinic $\mathrm{ZrO}_{2}{ }^{23,25-28}$ At starting conditions, where the background of the oxidized pellet was taken in vacuum of $10^{-5} \mathrm{mbar}$, there are already $\mathrm{OH}$-groups present at the surface. If additional water molecules adsorb via hydrogen bonds to these hydroxyl species, the binding state of the H-O-bond changes leading to negative peaks in the ratio spectrum. The bands are red-shifted to $3700 \mathrm{~cm}^{-}$ ${ }^{1}$ and $3610 \mathrm{~cm}^{-1}$ representing the first surface-near layer (consisting of $\mathrm{OH}$ and ice-like structured water molecule network). This is supported by Kouva et. al. ${ }^{23}$ but also by studies on other oxides like $\mathrm{Fe}_{2} \mathrm{O}_{3}{ }^{29}$ and $\mathrm{TiO}_{2}{ }^{24,30}$. The broad feature between $\sim 3600-2800 \mathrm{~cm}^{-1}$ indicates H-bonded water und thus, both the ice-like layer and polymeric chained water with a comparably low impact on the oxide surface. The broadness of this feature is due to several possible $\mathrm{OH}$ bond-lengths/strengths being in a more dynamic intermolecular interaction as compared to the structurally "fixed" species at lower amounts of adsorbed water. Obviously, the wavenumber region above $2800 \mathrm{~cm}^{-1}$ contains a lot of information, but also below 1700 
$\mathrm{cm}^{-1}$ distinct changes in the spectra, caused by water, are present. The peak at $1645 \mathrm{~cm}^{-1} \mathrm{can}$ be assigned to the $\delta(\mathrm{OH})$ bending of physisorbed (multilayer, polymeric chained) water ${ }^{24,30}$. As in the $\mathrm{OH}$ stretching region, negative peaks (below $1400 \mathrm{~cm}^{-1}$ ) could be assigned to isolated $\mathrm{OH}$ groups, but in the case of $\mathrm{ZrO}_{2}$ these signals are ill-defined at low pressures and the signals for gaseous water do interfere strongly at pressures higher than $10^{-2}$ mbar.

The comparison of $\mathrm{H}_{2} \mathrm{O}$ and $\mathrm{D}_{2} \mathrm{O}$ adsorption on $\mathrm{ZrO}_{2}$ is shown in Figure 2B. Although the purity of the used $\mathrm{D}_{2} \mathrm{O}$ is $99.9 \%$, a small contamination with water could not be avoided. In fact, a pressure of $5 \cdot 10^{-2}$ mbar $\mathrm{H}_{2} \mathrm{O}$ resembles the effect of $\mathrm{H}_{2} \mathrm{O}$ in 24 mbar $\mathrm{D}_{2} \mathrm{O}$. Upon increasing the pressure of $\mathrm{D}_{2} \mathrm{O}$ (not shown here), at first, only signals for the $\mathrm{H}_{2} \mathrm{O}$ impurities are visible (up to a pressure range of $10^{-2}$ mbar) before $\mathrm{H}_{2} \mathrm{O}$ saturation signals for $\mathrm{D}_{2} \mathrm{O}$ arise. For $\mathrm{H}_{2} \mathrm{O}$ this includes the exactly same negative signals for the $\mathrm{t}-\mathrm{OH}\left(3780 \mathrm{~cm}^{-1}\right)$ and $\mathrm{m}-\mathrm{OH}$ $\left(3670 \mathrm{~cm}^{-1}\right)$ groups which are shifted to peaks at $3700 \mathrm{~cm}^{-1}$ and $3610 \mathrm{~cm}^{-1}$ along with the broad feature between $3600 \mathrm{~cm}^{-1}$ and $2800 \mathrm{~cm}^{-1}$ and a $\delta(\mathrm{OH})$ peak at $1645 \mathrm{~cm}^{-1}$. The additional signals for adsorbed $\mathrm{D}_{2} \mathrm{O}$ are a sharp peak for OD-stretching at $2720 \mathrm{~cm}^{-1}$ (ice-like $\mathrm{D}_{2} \mathrm{O}$ near the surface), a broad feature (polymeric chained $\mathrm{D}_{2} \mathrm{O}$ ) from $2710 \mathrm{~cm}^{-1}$ to $\sim 1960 \mathrm{~cm}^{-}$ ${ }^{1}$ and $\delta(\mathrm{OD})$ vibration peaks at $1502 \mathrm{~cm}^{-1}$ and $1360 \mathrm{~cm}^{-1}$.

Isothermal water adsorption on YSZ is shown in Figure 2C. In comparison to the experiment on $\mathrm{ZrO}_{2}$, there are much more changes in the infrared spectra visible. In principle, more water can be adsorbed, since the relative changes in the spectra of YSZ are much more pronounced, especially in the $\delta(\mathrm{OH})$ region. The absorbance in Figure 2 is not normalized to the specific surface area and thickness of the sample pellet, but for a better comparability, this was done in in Figure 3. Nevertheless, although the specific surface area of the used YSZ is higher than for the used $\mathrm{ZrO}_{2}$, the capacity of water adsorption is higher for YSZ (see also discussion below). Doping monoclinic $\mathrm{ZrO}_{2}$ with $8 \mathrm{~mol} \% \quad \mathrm{Y}_{2} \mathrm{O}_{3}$ leads to a tetragonal phase with an increased amount of surface defects leading to an increased amount of dissociation sites for water. Thus, at the starting conditions of the isothermal experiment, there are more $\mathrm{OH}$ groups 
present on $\mathrm{YSZ}$ than on $\mathrm{ZrO}_{2}$, strongly influencing/promoting further water uptake due to the increased polarity of the surface and the possibility of stabilization via hydrogen bonds.

In the wavenumber region for $\mathrm{OH}$ stretching modes there are similar changes taking place as on pure $\mathrm{ZrO}_{2}$. The negative peaks for isolated $\mathrm{OH}$-groups are at $3770 \mathrm{~cm}^{-1}$ and $3682 \mathrm{~cm}^{-1}$. These signals are red-shifted to $3701 \mathrm{~cm}^{-1}$ and $3656 \mathrm{~cm}^{-1}$. A noticeable difference between $\mathrm{ZrO}_{2}$ and $\mathrm{YSZ}$ is the fact that on $\mathrm{ZrO}_{2}$ the signal for the $\mathrm{t}-\mathrm{OH}$ is more pronounced and on $\mathrm{YSZ}$ $\mathrm{m}-\mathrm{OH}$ seems to be the more frequent species. The obvious explanation is again the doping with $\mathrm{Y}_{2} \mathrm{O}_{3}$, since on every defect near an $\mathrm{Y}^{3+}$ center, a m-OH group can be formed.

The signal for $\mathrm{O}-\mathrm{H}$ bending for polymeric chained water is shifted with increasing pressure from $1605 \mathrm{~cm}^{-1}$ (up to $10^{-1} \mathrm{mbar}$ ) to $1636 \mathrm{~cm}^{-1}$ (24 mbar). There are significant negative peaks at $1330 \mathrm{~cm}^{-1}$ and $1038 \mathrm{~cm}^{-1}$, which can be referred to $\delta(\mathrm{OH})$ vibrations of the isolated hydroxyl groups. The evolution of the other peaks is quite complex during pressure increase (see also Figure S2): at pressures below $2 \cdot 10^{-1}$ mbar there are peaks at $1305 \mathrm{~cm}^{-1}, 1138 \mathrm{~cm}^{-1}$, $1224 \mathrm{~cm}^{-1}$ and $1052 \mathrm{~cm}^{-1}$. Interestingly, at $2 \cdot 10^{-1}$ mbar a change in the spectra is observed. As already mentioned, the $\delta(\mathrm{OH})$ peak for polymeric chained water is constantly shifted to higher wavenumbers above this pressure and the other remaining peaks are also constantly changing to $1217 \mathrm{~cm}^{-1}$ and $1104 \mathrm{~cm}^{-1}$ at 24 mbar. This indicates a structurally quite more complex layer growth than on $\mathrm{ZrO}_{2}$. Although a detailed discussion of every peak cannot be offered at this point, the explanation for the changes is the influence of Y in YSZ compared to pure $\mathrm{ZrO}_{2}$. As mentioned above, doping of $\mathrm{ZrO}_{2}$ with $8 \mathrm{~mol} \% \mathrm{Y}_{2} \mathrm{O}_{3}$ does certainly not only change structural parameters like the crystallographic phase (monoclinic to tetragonal) and specific surface area ( $2 \mathrm{~m}^{2} \mathrm{~g}^{-1}$ to $\left.32 \mathrm{~m}^{2} \mathrm{~g}^{-1}\right)$, but also the chemical adsorption behavior towards water due to the introduction of defects/more dissociation sites and the creation of additional Y-binding sites. $\mathrm{D}_{2} \mathrm{O}$ adsorption on YSZ (Figure 2D) leads to an additional O-D stretching peak at $2680 \mathrm{~cm}^{-1}$ for ice-like $\mathrm{D}_{2} \mathrm{O}$ and a broad feature from $2670 \mathrm{~cm}^{-1}$ to $\sim 1950 \mathrm{~cm}^{-1}$. The signals for the $\mathrm{H}_{2} \mathrm{O}$

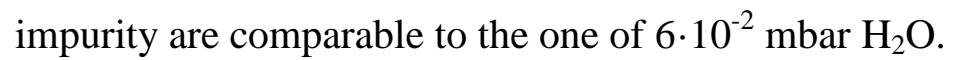


Since the changes in the delta OH/OD region are already quite pronounced for $\mathrm{H}_{2} \mathrm{O}$ adsorption, it was not possible to determine any specific peaks for a delta O-D mode, due to the fact that the fingerprint in this region looks very similar to the one in $6 \cdot 10^{-2}$ mbar pure $\mathrm{H}_{2} \mathrm{O}$.

Water adsorption on $\mathrm{Y}_{2} \mathrm{O}_{3}$ is shown in Figure $2 \mathrm{E}$. $\mathrm{Y}_{2} \mathrm{O}_{3}$ is a very hygroscopic oxide which is reflected in the infrared data for water adsorption. The modes of adsorbed water are much more complex than for the other two oxides indicating a variety of binding sites or discrete adsorption states. In fact, $\mathrm{Y}_{2} \mathrm{O}_{3}$ has a much larger specific surface area than the other two oxides $\left(120 \mathrm{~m}^{2} \mathrm{~g}^{-1}\right)$, increasing the possibility of a higher number of separated $\mathrm{H}_{2} \mathrm{O}$ islands or $\mathrm{OH}$ groups/dissociation sites. Additionally, the dynamic sorption measurements in section 3.3 prove that incorporation of water molecules forming extended hydroxide domains takes place. Thus, already from the infrared data we can state that the general concept of water adsorption on oxides derived from literature in section 3.1 is not valid for $\mathrm{Y}_{2} \mathrm{O}_{3}$, which rather becomes hydrolysed towards its hydroxide, along with crystal water inclusion. In fact, water uptake is more comparable to e.g. the $\mathrm{CaO}$ vs. $\mathrm{Ca}(\mathrm{OH})_{2}$ system. One negative peak at $3678 \mathrm{~cm}^{-1}$ can be referred to a multi-coordinated $\mathrm{OH}$ group on $\mathrm{Y}_{2} \mathrm{O}_{3}$. Already at a pressure of $2 \cdot 10^{-3} \mathrm{mbar}$, there are several strong peaks at $3706 \mathrm{~cm}^{-1}, 3672 \mathrm{~cm}^{-1}, 3619 \mathrm{~cm}^{-1}, 3549 \mathrm{~cm}^{-1}, 3524 \mathrm{~cm}^{-1}$ and 3480 $\mathrm{cm}^{-1}$. Comparing with $\mathrm{Ca}(\mathrm{OH})_{2}$, peaks above $\sim 3600 \mathrm{~cm}^{-1}$ can be referred to dissociated water and discrete peaks below $\sim 3600 \mathrm{~cm}^{-1}$ to crystal water. ${ }^{31}$ These peaks increase strongly up to a pressure of 1 mbar (compare also Figure S3), where the broad water feature gets significant and further increase of the water pressure leads to a superposition of most of the distinctive peaks by the polymeric chained water feature from $3660 \mathrm{~cm}^{-1}$ to $\sim 2500 \mathrm{~cm}^{-1}$ including a distinctive peak at $3690 \mathrm{~cm}^{-1}$ (representing structured water layers near the surface). The broad $\mathrm{OH}$ feature for adsorbed water at 24 mbar it extremely pronounced in comparison to the peaks of gaseous water, indicating a very strong water uptake up to high pressures. 
Also in the region for $\delta(\mathrm{OH})$ vibrations there are several peaks observed especially at pressures below 1 mbar. The most distinctive are at $1495 \mathrm{~cm}^{-1}, 1413 \mathrm{~cm}^{-1}, 1055 \mathrm{~cm}^{-1}, 1463$ $\mathrm{cm}^{-1}$ (negative) and $1317 \mathrm{~cm}^{-1}$ (negative). None of these peaks does match any peaks of the other two oxides. The mode for the $\delta(\mathrm{OH})$ vibration of polymeric chained water can be assigned to $1644 \mathrm{~cm}^{-1}$ at a pressure of 24 mbar.

$\mathrm{D}_{2} \mathrm{O}$ adsorption on $\mathrm{Y}_{2} \mathrm{O}_{3}$ is as complex as $\mathrm{H}_{2} \mathrm{O}$ adsorption. Similar to the other oxides the spectra in 24 mbar $\mathrm{D}_{2} \mathrm{O}$ can be compared to a $\mathrm{H}_{2} \mathrm{O}$ pressure of $1 \cdot 10^{-2}$ mbar. Besides the above mentioned $\mathrm{OH}$ signals for the $\mathrm{H}_{2} \mathrm{O}$ impurities there are distinct O-D stretching modes at 2732 $\mathrm{cm}^{-1}, 2709 \mathrm{~cm}^{-1}, 2670 \mathrm{~cm}^{-1}, 2620 \mathrm{~cm}^{-1}$ and $2607 \mathrm{~cm}^{-1}$. Like on YSZ, the delta O-D modes are hard to distinguish because of the strong superimposition with the water delta $\mathrm{OH}$ signals.

An additional comment on the high amount and reactivity of the $\mathrm{OH}$ groups on $\mathrm{Y}_{2} \mathrm{O}_{3}$ should be added in comparison to other adsorption studies with $\mathrm{CO}$ and $\mathrm{CO}_{2} \cdot{ }^{16}$ In general, a certain amount of hydroxylation is necessary for a good catalytic activity, but as also stated by Moreau et al. ${ }^{4}$, too many hydroxyl groups can cause an activity loss. This is corroborated by the fact that on $\mathrm{Y}_{2} \mathrm{O}_{3}$ carbonates (chemisorption of $\mathrm{CO}_{2}$ ) cannot be removed in oxidative atmosphere up to $1173 \mathrm{~K} .{ }^{19}$ All assignable vibrations on $\mathrm{ZrO}_{2}$, YSZ and $\mathrm{Y}_{2} \mathrm{O}_{3}$ are jointly summarized in Table S1.

From the FT-IR data, more information can be obtained by plotting the relative height/absorbance of the broad water feature against the partial pressure. Since the water gas phase modes increasingly screen this analysis at pressures $>10^{-2}$ mbar especially on $\mathrm{ZrO}_{2}$, this was done at a wavenumber of $3160 \mathrm{~cm}^{-1}$ where the signal intensity of gaseous water is zero (Q-branch of the first overtone of the delta rotational-vibrational mode ${ }^{32}$, see magnification in Figure S1). The resulting trend is plotted in Figure 3. Note that the data are shown up to a $\mathrm{p} / \mathrm{p}_{0}$ value of 0.6 due to the fact that the liquid-like layers do not contribute to the infrared signal. For the direct comparison of the oxides, the absorbance values were 
normalized to the specific surface area and the sample mass (directly correlated with the thickness of the pellet).

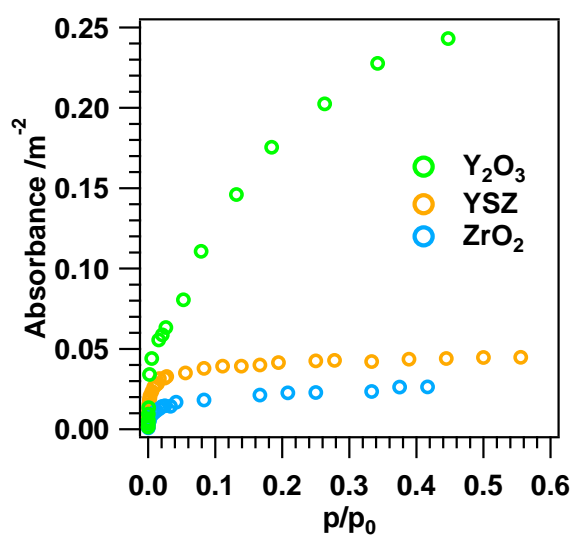

Figure 3: Plot of the absorbance at $3160 \mathrm{~cm}^{-1}$ of $\mathrm{ZrO}_{2}$ (blue), $\mathrm{YSZ}$ (yellow) and $\mathrm{Y}_{2} \mathrm{O}_{3}$ (green) normalized to sample mass and surface area.

At pressures below $\sim 1 \mathrm{mbar}\left(\mathrm{p} / \mathrm{p}_{0}=0.04\right)$ on all samples a drastic increase of the absorbance at $3160 \mathrm{~cm}^{-1}$ is observed and for $\mathrm{ZrO}_{2}$ (Figure 3, blue dots) and YSZ (Figure 3, yellow dots) any further increase of the water vapor pressure has a reduced impact on the absorbance at this wavenumber. Two processes of water adsorption can be derived from this plot: the irreversible growth of the ice-like water layer expressed by the first steep increase, and, once this layer reaches its maximum, only the adsorption of the polymeric chained water molecules is observed. In this context we also refer to the correlation with the dynamic sorption measurements in section 3.3. The adsorption behavior of $\mathrm{Y}_{2} \mathrm{O}_{3}$ is distinctly different from that of the other two oxides. Its hygroscopic nature is expressed especially by the fact that water molecules are incorporated, and thus, evaluating the data at $3160 \mathrm{~cm}^{-1}$ (Figure 3, green dots) leads to a very different course of the absorbance as for the other two oxides.

Figure 3 again reflects the general capacity of water uptake for the oxides: $\mathrm{Y}_{2} \mathrm{O}_{3}>\mathrm{YSZ}>$ $\mathrm{ZrO}_{2}$. Comparing YSZ and $\mathrm{ZrO}_{2}$, not only with respect to the total amount of adsorbed water but also the capacity of molecules in the ice-like layer, the steep increase for the lower partial pressures is higher for $\mathrm{YSZ}$ than for $\mathrm{ZrO}_{2}$. 
Comparing the infrared data of the three oxides to the generalized concept in Figure 1, it is obvious that distinct differences concerning $\mathrm{H}_{2} \mathrm{O}$ adsorption are observed. Due to the fact that on $\mathrm{Y}_{2} \mathrm{O}_{3}$ an extended hydroxide layer along with crystal water is formed, the adsorption on this oxide cannot be directly compared to $\mathrm{ZrO}_{2}$ and YSZ, but this process is also crucially different to the generalized adsorption of water stated in section 3.1. For $\mathrm{ZrO}_{2}$ and $\mathrm{YSZ}$, the concept is valid to a certain extent, but the fact is striking that the amount of active sites - and thus the actual amount of already dissociated $\mathrm{OH}$-groups - on these oxides, which is strongly influenced by doping $\mathrm{ZrO}_{2}$ with $\mathrm{Y}_{2} \mathrm{O}_{3}$, affects the growth of both the ice-like layer and the subsequent polymeric chained layers.

\subsection{Dynamic moisture sorption experiments}

For the dynamic moisture sorption experiments the relative humidity is set by mixing a flow of dry air with a flow of water saturated air. The minimum moisture of the dry air flow is $1 \%$ relative humidity, implying that, although the oxide powders were pre-oxidized up to $1273 \mathrm{~K}$, the surface of the particles provides not only hydroxyl groups but also a full occupation of the ice-like layer. In contrast to the FT-IR setup, the moisture sorption setup provides a dynamic atmosphere. This method evaluates roughly the state of the samples above the bend in the plot of the absorbance at $3160 \mathrm{~cm}^{-1}$ versus the partial pressure in Figure 3.
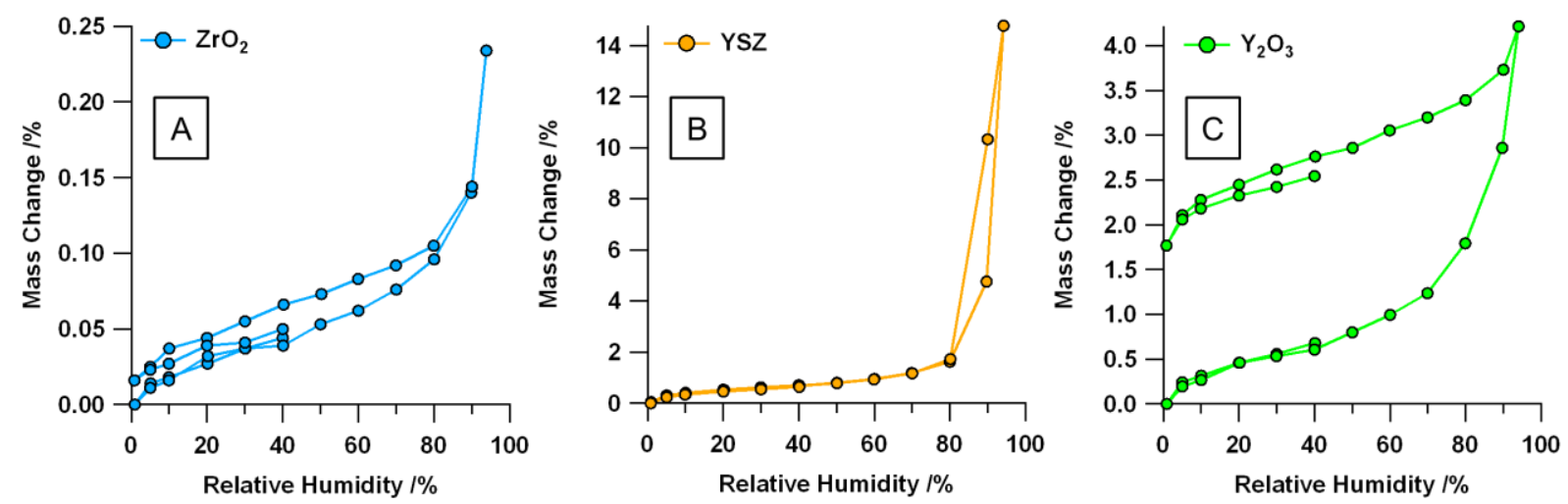

Figure 4: Dynamic moisture sorption measurements of $\mathrm{ZrO}_{2}(\mathrm{~A}), \mathrm{YSZ}(\mathrm{B})$ and $\mathrm{Y}_{2} \mathrm{O}_{3}(\mathrm{C})$. 
For $\mathrm{ZrO}_{2}$ (Figure 4A) and $\mathrm{YSZ}$ (Figure 4B) a reversible adsorption-desorption cycle is deduced, in contrast to $\mathrm{Y}_{2} \mathrm{O}_{3}$. The hysteresis over the whole relative humidity range in Figure 4C together with the FT-IR data for $\mathrm{Y}_{2} \mathrm{O}_{3}$ strongly indicates that water is more or less irreversibly incorporated into the crystal structure. Thus, the observed uptake of at maximum $\sim 4 \%$ mass change on $\mathrm{Y}_{2} \mathrm{O}_{3}$, which is quite low compared to YSZ, is just 'the tip of the iceberg'. On YSZ, as well as on $\mathrm{ZrO}_{2}$, no uptake of crystal water can be observed. According to Sing et. al. ${ }^{33}$ the course of the moisture sorption on YSZ is HI-type. The shape of this loop is often associated with porous materials known to consist of agglomerates (or compacts of uniform spheres). Especially on YSZ, capillary condensation is pronounced above $80 \%$ relative humidity, where the mass change increases from $\sim 1.5 \%$ to $13.3 \%$. In comparison, the mass change on $\mathrm{ZrO}_{2}$ at $80 \%$ relative humidity is $\sim 0.1 \%$ and the maximum mass change on $\mathrm{ZrO}_{2}$ is $0.23 \%$. The sorption data are again reflecting the general findings of the FT-IR data in 3.2: the general capacity to adsorb water is sufficiently increased for YSZ in comparison to $\mathrm{ZrO}_{2}$, which cannot be derived only by the different surface areas but actually by the amount of $\mathrm{OH}$ groups on the surface. Calculated from the mass change in the sorption data and the known surface area, the uptake of water can also be expressed by mol $\mathrm{H}_{2} \mathrm{O}$ per $\mathrm{m}^{2}$ oxide surface (see Figure $5 \mathrm{~A}$ ). 

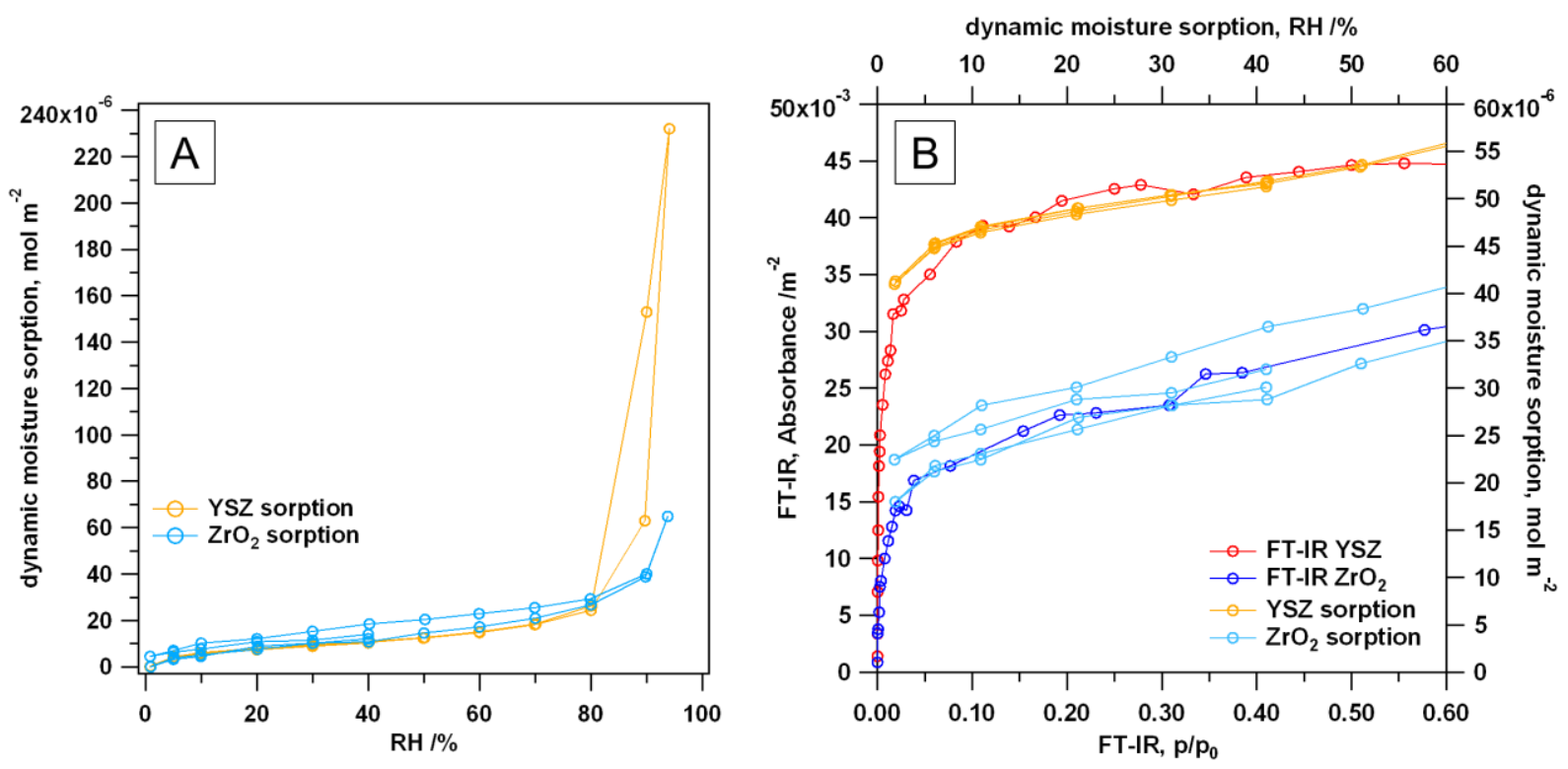

Figure 5: (A) Dynamic moisture sorption measurements of $\mathrm{ZrO}_{2}$ (blue), YSZ (yellow) in mol $\mathrm{H}_{2} \mathrm{O}$ per $\mathrm{m}^{2}$ oxide surface; (B) determination of the 'offset' for the sorption experiment compared to the FT-IR evaluation at $3160 \mathrm{~cm}^{-1}$.

Comparing the uptaken mol $\mathrm{H}_{2} \mathrm{O}$ per $\mathrm{m}^{2}$ oxide surface of $\mathrm{YSZ}$ and $\mathrm{ZrO}_{2}$, Figure 5A proves that the water uptake per square meter available surface is actually the same up to $80 \%$ humidity but on YSZ the capillary condensation at higher water pressures is pronounced. As the isothermal water uptake is evaluated on samples with an already existing ice-like layer, the zero point in Figure 5A is certainly not zero when the full amount of already pre-adsorbed $\mathrm{H}_{2} \mathrm{O}$ molecules is taken into account. Since the evaluation of the FT-IR data at $3160 \mathrm{~cm}^{-1}$ provides this supplemental information, a comparison to estimate the offset of the dynamic moisture sorption measurements is provided in Figure 5B by plotting the FT-IR absorbance per $\mathrm{m}^{2}$ on the left axis and the mol $\mathrm{H}_{2} \mathrm{O}$ per $\mathrm{m}^{2}$ on the right axis. With the knowledge that the lowest relative humidity in the dynamic moisture sorption experiment is $1 \%$, this $\mathrm{x}$-offset was set for the respective data. Additionally, an appropriate y-offset for the dynamic moisture sorption data was chosen for correlation with the FT-IR course after the bend. The obtained yoffset is $4.1 \cdot 10^{-5} \mathrm{~mol} \mathrm{~m}{ }^{-2}$ for YSZ $\left(2.5 \cdot 10^{19} \mathrm{H}_{2} \mathrm{O}\right.$ molecules $\mathrm{m}^{-2}$, which would be additional $0.0104 \%$ mass change) and $1.8 \cdot 10^{-5} \mathrm{~mol} \mathrm{~m} \mathrm{~m}^{-2}$ for $\mathrm{ZrO}_{2}\left(1.1 \cdot 10^{19} \mathrm{H}_{2} \mathrm{O}\right.$ molecules $\mathrm{m}^{-2}$, 
additional $0.0015 \%$ mass change). According to Raz et. al. ${ }^{13}$ the area per molecularly adsorbed $\mathrm{H}_{2} \mathrm{O}$ on YSZ is $10.8 \AA^{2}$ and the area per surface $\mathrm{Zr}$ center is at minimum $14.6 \AA^{2}$. Assuming that a hypothetical monolayer of molecularly adsorbed water on YSZ is " $\mathrm{H}$-atominterconnected" (promoted by the high amount of surface $\mathrm{OH}$ groups, leading to conduction in the EIS measurements, see also section 3.4), $10.8 \AA^{2}$ can be used as reference. On $\mathrm{ZrO}_{2}$ the $\mathrm{H}_{2} \mathrm{O}$ molecules are mainly bonded to the $\mathrm{Zr}$-centers in a hypothetical monolayer of water (no conduction in the EIS data in section 3.4) and thus, 14.6 $\AA^{2}$ should be taken as reference for the monolayer estimation. The water binding capacity of the ice-like water on YSZ is therefore roughly $\sim 2.7 \mathrm{ML}$ and for $\mathrm{ZrO}_{2} \sim 1.6 \mathrm{ML}$. The further uptake of polymeric chained water up to $80 \%$ relative humidity equals the amount of water in roughly $\sim 2$ additional ML for both oxides.

Comparing these findings to the generalized concept in section 3.1, these values again confirm the assumption that $\mathrm{ZrO}_{2}$ is less hydroxylated than YSZ, which strongly lowers not only the amount of water in the ice-like layer, but also alters the binding mode. The higher amount of water in the ice-like layer on YSZ is clearly related to the higher amount of $\mathrm{OH}$ groups/defects on the surface (increased polarity, better stabilization of the layer via hydrogen bonds to the surface) than for $\mathrm{ZrO}_{2}$. The "few" OH-groups on $\mathrm{ZrO}_{2}$ are, compared to YSZ, too far away of each other to sufficiently stabilize a total hydrogen-bonded wetting of the surface. In contrast, on YSZ a good stabilization of the $\mathrm{OH}$-covered surface is likely for the ice-like layer and thus, the capacity of water uptake in this layer is increased relative to the un-doped oxide.

Since we assume that the ice-like layer is complete around the bend of the FT-IR plot in Figure 4 and Figure 5B, for every surface-normalized absorbance value a coverage with an associated pressure can be extracted from the data. Using the rough but usual approximation of a Langmuir model for this ice-like layer ${ }^{13}$, a desorption enthalpy $\Delta \mathrm{H}$ of $\sim 56 \mathrm{~kJ} \mathrm{~mol}^{-1}$ for both oxides can be estimated. Furthermore, with this knowledge the temperature dependency 
of the coverage within the ice-like layer on $\mathrm{ZrO}_{2}$ and $\mathrm{YSZ}$ can be calculated: The coverage of the ice-like layer approaches zero around $\sim 500 \mathrm{~K}$ at an equilibrium pressure of 24 mbar (see also Figure S4).

\subsection{Electrochemical impedance spectroscopy}

All impedance measurements are conducted in a flowing isobaric atmosphere of different partial pressures of water (He as carrier gas, flow $\sim 1 \mathrm{~mL} \mathrm{~s}^{-1}$ ). The samples are pre-treated in dry $\mathrm{O}_{2}$ up to $1273 \mathrm{~K}$, directly followed by the treatment in moist He without any contact to air. Thus, before water contact, the samples are assumed to provide comparable starting conditions (hydroxylated surface, no additional water layer) to the infrared experiments. Two distinct water partial pressures, 4 mbar and 24 mbar, were chosen. The starting point in the impedance spectra therefore represents the pre-treated sample that is exposed to a flowing water vapor/ helium stream leading to equilibrium water adsorption at the respective partial pressure. 4 mbar correspond to $17 \%$ relative humidity, which is comparable to the sorption data in Figure 4 at the beginning of the "plateau", representing polymeric chained/clustered water. 24 mbar correspond to almost $100 \%$ humidity near the saturation vapor pressure of water, i.e. near condensation, and thus, liquid-like water. Upon isobaric heating, more information about the contribution of water layers and hydroxylation to the impedance course can be obtained. For the most detailed comparison to the water experiments, Figure S5 provides correlating experiments in pure and dry He to distinguish the temperature-induced conduction contributions from the ones induced by $\mathrm{H}_{2} \mathrm{O} / \mathrm{D}_{2} \mathrm{O}$ (t- and $\mathrm{m}-\mathrm{OH}$, ice-like water \& polymeric chained water).

The study of Raz et al $^{13}$ provides a detailed theoretical background of the conductivity phenomenon of the different water layers on YSZ. Their perception of the layer model is basically consistent with the one stated in here. According to this study, the proton conduction in the chemisorbed water layer includes defect formation and proton hopping strongly associated with defects involving ' $\mathrm{ZrO}$ ' and ${ }^{2} \mathrm{ZrOH}_{2}{ }^{+}$' pairs. The conduction in the first 
physisorbed water layer is dominated by $\mathrm{H}_{3} \mathrm{O}^{+}$and $\mathrm{OH}^{-}$and the proton conduction in a few physisorbed water layers is expressed by hydronium propagation $\mathrm{H}_{3} \mathrm{O}^{+}+\mathrm{H}_{2} \mathrm{O} \rightarrow \mathrm{H}_{2} \mathrm{O}+$ $\mathrm{H}_{3} \mathrm{O}^{+}$. There is a huge difference in the adsorption enthalpies of chemisorption (of the order of $100 \mathrm{kJmol}^{-1}$ ) and physisorption on top of the chemisorbed layers (a few $\mathrm{kJmol}^{-1}$ to tens of $\mathrm{kJmol}^{-1}$ ) which is expressed by the fact that Raz et al. conclude that chemisorption plays a role up to a few hundred ${ }^{\circ} \mathrm{C}$ (chemisorbed layer is more than $50 \%$ complete below $\sim 723 \mathrm{~K}$ and physisorption below $\mathrm{T}<423 \mathrm{~K}$ ). However, the above mentioned study provides investigations in at max. $3 \mathrm{~mol} \% \mathrm{H}_{2} \mathrm{O}$ in $\mathrm{O}_{2}$ or air up to max. $1073 \mathrm{~K}$ and it focusses exclusively on the pure conductivity contributions in/of the water layers. The present study is in good correlation with these results, but with the difference that we examine the whole oxide system in moist atmosphere up to a partial pressure of water near 1 .

Additionally, Sato et al. ${ }^{34}$ provide information about theoretical conduction mechanisms on hydrated $\mathrm{ZrO}_{2}$ via proton migration on a cubic $\mathrm{ZrO}_{2}$ (110) surface with hierarchically hydrogen-bonded $\mathrm{H}_{2} \mathrm{O}$ layers and also chemisorbed species. Again the conductivity is directly

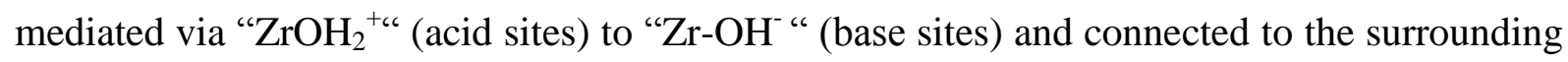
chained $\mathrm{H}_{2} \mathrm{O}$ molecules.

Before the discussion of the EIS experiments in $\mathrm{H}_{2} \mathrm{O}$ and $\mathrm{D}_{2} \mathrm{O}$, a brief note about ultra-pure water (UPW) should be provided. It is already known from literature ${ }^{35}$ that UPW has a conductivity of $\kappa=0.05501 \mu \mathrm{S} \mathrm{cm}^{-1}$ and hence, a resistivity of $\rho=18.18 \mathrm{M} \Omega \mathrm{cm}$ at $298 \mathrm{~K}$ (cf. at $373 \mathrm{~K}: \kappa=0.7849 \mu \mathrm{S} \mathrm{cm}^{-1}, \rho=1.274 \mathrm{M} \Omega \mathrm{cm}$ ). However, these measurements are very sensitive to error sources (temperature ramps, used resistance temperature devices introduction of gaseous or dissolved impurities during heating). With this knowledge one can assume that upon treatment of our samples in $\mathrm{H}_{2} \mathrm{O} / \mathrm{D}_{2} \mathrm{O}$ also lower impedance values in the $\mathrm{M} \Omega$ range in the low temperature region with liquid-like water "condensation" should be approached, if the surface is easily wetted (e.g. because of strong hydroxylation) and, thus, favors the formation of fully interconnected water layers. 

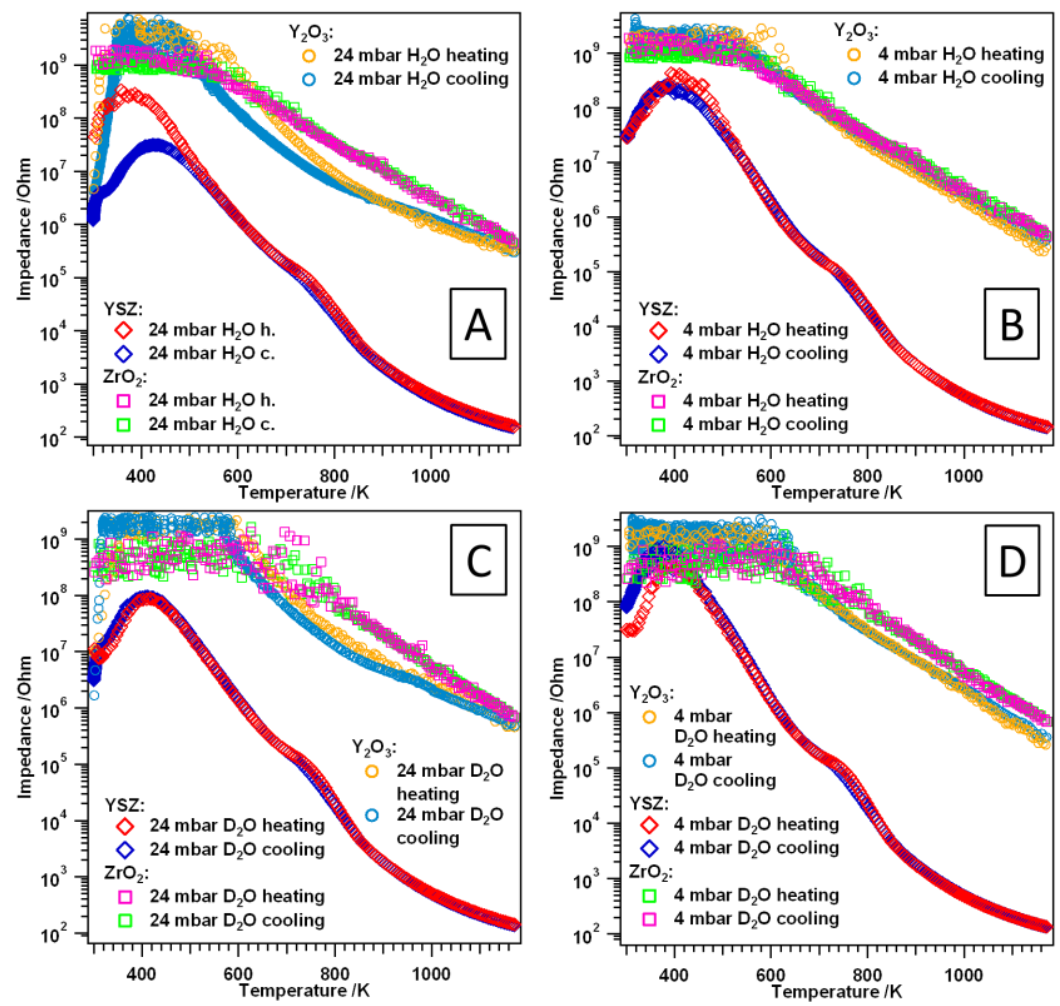

Figure 6: Temperature-dependent electrochemical impedance measurements on $\mathrm{Y}_{2} \mathrm{O}_{3}, \mathrm{YSZ}$ and $\mathrm{ZrO}_{2}$ in flowing $\mathrm{He}\left(\sim 1.0 \mathrm{~mL} \mathrm{~s}^{-1}\right)$ saturated with 24 and 4 mbar $\mathrm{H}_{2} \mathrm{O}$ (panel A and $\mathrm{B}$ ), 24 and 4 mbar $\mathrm{D}_{2} \mathrm{O}$ (panel $\mathrm{C}$ and $\mathrm{D}$ ). Linear heating and cooling rates of $10 \mathrm{~K} \mathrm{~min}^{-1}$ between $\mathrm{RT}$ and $1173 \mathrm{~K}$ were applied; "c" = cooling, "h" = heating.

\section{Treatment in 4 and 24 mbar $\mathrm{H}_{2} \mathrm{O}$ and $\mathrm{D}_{2} \mathrm{O}$}

The electrochemical impedance measurements in Figure 6A-D (red and dark blue traces) show that water treatment of the YSZ sample in all four gas atmospheres (4 and 24 mbar either $\mathrm{H}_{2} \mathrm{O}$ or $\mathrm{D}_{2} \mathrm{O}$ ) between room temperature (RT) and $1173 \mathrm{~K}$ leads to a similar trend during heating and cooling. An impedance value at RT of $\sim 4 \cdot 10^{7} \Omega$, which is about 2 magnitudes lower than under dry conditions, is obtained at the beginning of the heating routine. Upon heating between $\mathrm{RT}-410 \mathrm{~K}$ the impedance is rising, which is due to the removal of the physisorbed water multilayers contributing to a higher conductivity. This is also exactly the beginning of the first Arrhenius-fitted temperature region for the heating and cooling procedures (408 - $515 \mathrm{~K}$; depending on the used gas treatment and pressure) in the 
corresponding Arrhenius plot (Figure 7C and Table S2). Starting at T $>410 \mathrm{~K}$ the impedance starts to drop, exhibiting semiconductive behavior (final value of $\sim 1 \cdot 10^{2} \Omega$ at $1173 \mathrm{~K}$ ). During re-cooling, almost the exact same impedance course is apparent, and in 4 mbar $\mathrm{H}_{2} \mathrm{O}$ and $\mathrm{D}_{2} \mathrm{O}$ final values in the $10^{7} \Omega$ range are again attained at RT. On the YSZ samples treated in 24 mbar $\mathrm{H}_{2} \mathrm{O} / \mathrm{D}_{2} \mathrm{O}$ the impedance drops to even lower values in the $10^{6} \Omega$ range. Another general characteristic feature is visible in the temperature-dependent impedance spectra of YSZ in the area between $673 \mathrm{~K}-873 \mathrm{~K}$ as a "bump" at $\sim 750 \mathrm{~K}$ (note that this is exactly the temperature where two different temperature regimes with different $\mathrm{E}_{\mathrm{A}}$ 's are present in the Arrhenius plot in Figure 7 and Table S2). It is already known from comparable studies ${ }^{18,19}$ that different areas in the whole temperature-range can be defined, where changes of charge transfer mechanisms, e.g. at grain boundaries, contribute to the total impedance/conductivity: in the additional He experiment in Figure S5, up to $\sim 750 \mathrm{~K}$ the impedance is strongly influenced by hydroxyl-mediated charge-transfer at the grain boundaries, and starting at $\mathrm{T}>$ $750 \mathrm{~K}$ pure oxide ion transfer is most likely becoming dominant due to progressive surface dehydroxylation.
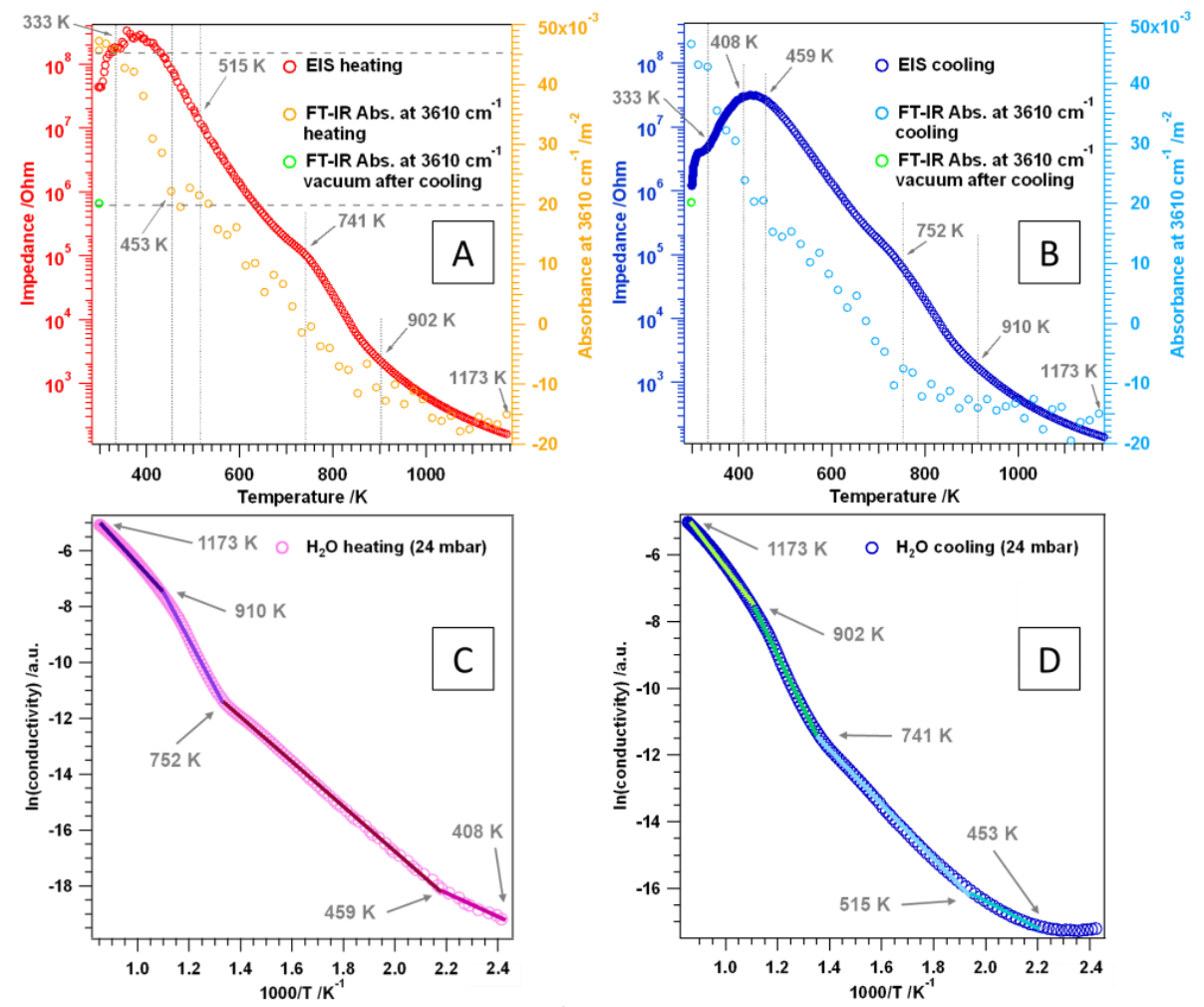
Figure 7: Correlation of EIS and FT-IR data on YSZ in $24 \mathrm{mbar}_{2} \mathrm{O}$ (flow $\sim 1 \mathrm{~mL} \mathrm{~s}^{-1}$, He carrier gas). Comparison of the electrochemical impedance with the relative FT-IR absorbance at $3160 \mathrm{~cm}^{-1}$ upon (A) heating and (B) cooling. Corresponding Arrhenius plots of (C) heating and (D) cooling electrochemical impedance traces in 24 mbar $\mathrm{H}_{2} \mathrm{O}$.

The exactly same experiment on YSZ in 24 mbar $\mathrm{H}_{2} \mathrm{O}$ was also performed in the FT-IR setup, monitoring especially the broad water feature at the characteristic wavenumber of $3160 \mathrm{~cm}^{-1}$. Upon plotting the absorbance of the IR signal at $3160 \mathrm{~cm}^{-1}$ and the impedance signal over the whole temperature range (Figure 7A and B, see also Figure S6), and comparing the qualitative course of both traces to the respective to Arrhenius fits (cf. Figure 7C and D and Table S2), the varying influence of physisorbed and chemisorbed water can be, at least qualitatively, extracted. Between RT and $333 \mathrm{~K}$ the infrared signal at $3160 \mathrm{~cm}^{-1}$ in Figure 7A stays constant even though there is an increase of almost 1 magnitude in the impedance signal. This confirms that the chosen wavenumber is not absolutely representative for all adsorbed water molecules. In fact, FT-IR is insensitive with respect to liquid-like water layers/molecules that are very far away from the surface where diffusional mobility/dynamic change of dipolar orientation of the whole water molecules becomes more likely. This is exactly the reason for the insensitivity of IR toward "liquid-like" condensed water in the measurements at $\mathrm{p} / \mathrm{p}_{0}$ values close to 1 , in comparison to the rather drastic increase in the sorption measurements in Figure 4B, which verify the expected condensation.

The first impedance rise (up to $\sim 350 \mathrm{~K}$ ) corresponds to the removal of water layers which are obviously IR-invisible (flat region in the absorbance plot) and exhibit a negative apparent activation energy with respect to charge carrier concentration (not plotted in Figure 7C). These "liquid" layers provide a pronounced conductivity-enhancing contribution (roughly corresponding to the conductivity of pure water ${ }^{35}$ ), contributing - along with the associated loss of conducting polymeric chained and ice-like species - to the strong resistivity increase 
upon removal, until the maximum position around $380 \mathrm{~K}$ is reached. Further heating leads to a fast decrease of the impedance, which nevertheless stays clearly below the values in dry He, due to the presence of both molecularly and dissociatively adsorbed water. The IR absorbance shows no such maximum, but a continuous and pronounced decrease of absorbance between $\sim 350$ and $\sim 450 \mathrm{~K}$. This means that above $350 \mathrm{~K}$ the "IR-visible", i.e. already rather surfacenear water species are desorbing, in the order polymeric-chained water, followed by ice-like water. This region corresponds to $\mathrm{p} / \mathrm{p}_{0}$ values between $<0.6$ (water partial pressures $<15$ mbar) in the adsorption isotherm of YSZ in Figure 3. As has been shown (Figure S5, equilibrium calculations in 3.3), temperatures around $450 \mathrm{~K}$ at 24 mbar equilibrium pressure are sufficient to deplete even the more strongly bonded ice-like layer (remaining after more or less complete desorption of the polymeric chain water) to $\sim 13 \%$ of its hypothetical Langmuir saturation value.

Further heating above $450 \mathrm{~K}$ leads to a less steep decrease in the infrared absorbance up to $900 \mathrm{~K}$ that is most likely associated with the further removal of remaining strongly bonded water molecules along with chemisorbed $\mathrm{OH}$ species. Above this temperature, the "negative" absorbance changes in the "broad feature" region (interconnected dense $\mathrm{OH}$ layer) are assigned to further dehydroxylation, i.e. depletion of chemisorbed water species (see also Figure S6). Re-cooling (Figure 7B) shows a similar trend: no OH-signal increase is observed until $\sim 900 \mathrm{~K}$, followed by a continuous re-hydroxylation/ dissociative water uptake upon further cooling to $\sim 500 \mathrm{~K}$. Subsequently, a faster increase in the course of the infrared signal is again observed in the region where the impedance exhibits a maximum $\left(\sim 3 \cdot 10^{7} \Omega\right)$ and drops again due to cumulative molecular water adsorption below $\sim 450 \mathrm{~K}$. At $333 \mathrm{~K}$ the impedance shows a small plateau $\left(\sim 4 \cdot 10^{6} \Omega\right.$, with a similar value in 24 mbar $\mathrm{D}_{2} \mathrm{O}$, Figure 6C), corresponding to an one magnitude lower impedance value in comparison to the $333 \mathrm{~K}$ point during heating. This plateau correlates with a step-like increase in the intensity of the IR signal as compared to the heating trace, suggesting even stronger hydroxylation during 
cooling and thus, an increased water capacity in the physisorbed layers (see also green "vacuum" reference data point in Figure 7B). Further cooling leads to a continuous decrease of the impedance to $\sim 1 \cdot 10^{6} \Omega$ at an almost constant infrared signal. The vacuum FT-IR spectrum after this heating and cooling routine reveals an increased amount of chemisorbed $\mathrm{m}-\mathrm{OH}$ groups at $3704 \mathrm{~cm}^{-1}$ (see also Figure S6). This is correlated with the smaller impedance value after cooling (in comparison to the start of the experiment) and is also reflected by a Nyquist plot with two semicircles (see detailed discussion below). Since the impedance experiments in 4 mbar $\mathrm{H}_{2} \mathrm{O}$ and $\mathrm{D}_{2} \mathrm{O}$ correspond to $17 \%$ humidity (beginning of the "polymeric chained water plateau" in the sorption measurement of Figure 4 with no liquidlike water layers) the plateau at $24 \mathrm{mbar} / 333 \mathrm{~K}$ is not observed and the impedance after the whole heating/cooling cycle is very similar to the value at the beginning $\left(\sim 3 \cdot 10^{7} \Omega\right.$, see Figure 6C and D). Table 2 gives an overview of the micro/macroscopic layer-by-layer model on which the interpretation/ quantification of the results is based. The impact of the four distinct adsorption categories of $\mathrm{H}_{2} \mathrm{O}$ on $\mathrm{YSZ}$ to the respective measurement techniques is summarized.

Table 2. Comparison of the impact of the distinct water adsorption models to the isothermal and isobaric FT-IR, sorption and EIS measurements on YSZ.

\begin{tabular}{|c|c|c|c|}
\hline YSZ & FT-IR signal at $3160 \mathrm{~cm}^{-1}$ & $\begin{array}{l}\text { sorption } \\
\text { measurement }\end{array}$ & EIS \\
\hline $\begin{array}{l}\text { liquid-like water } \\
\text { layers }\end{array}$ & $\begin{array}{l}\text { impact on the signal at } \\
\text { isothermal conditions: } \\
\text { no effect on IR signal } \\
\text { removal/uptake isobaric } \\
\text { conditions: } \\
\mathrm{T}<333 \mathrm{~K}\end{array}$ & $\begin{array}{l}\text { strong increase above } \\
80 \% \text { relative humidity }\end{array}$ & $\begin{array}{c}\text { removal/uptake isobaric } \\
\text { conditions: } \\
\mathrm{RT}-333 \mathrm{~K} \\
24 \mathrm{mbar} \mathrm{H}_{2} \mathrm{O} / \mathrm{D}_{2} \mathrm{O} \text { : } \\
\text { impedance at } \mathrm{RT} \\
\sim 1 \cdot 10^{6} \Omega\end{array}$ \\
\hline $\begin{array}{l}\text { polymeric chained } \\
\text { water molecules }\end{array}$ & $\begin{array}{c}\text { impact on the signal at } \\
\text { isothermal conditions }(R T) \text { : } \\
\mathrm{p}>1 \text { mbar } \\
\text { removal/uptake isobaric } \\
\text { conditions: } \\
333 \mathrm{~K}<\mathrm{T}<500 \mathrm{~K}\end{array}$ & $\begin{array}{l}\text { region between } 1 \% \text { and } \\
80 \% \text { relative humidity }\end{array}$ & $\begin{array}{c}\text { removal/uptake isobaric } \\
\text { conditions: } \\
333-380 \mathrm{~K} \\
24 \text { mbar } \mathrm{H}_{2} \mathrm{O} / \mathrm{D}_{2} \mathrm{O}: \\
\text { impedance at RT } \\
\sim 3 \cdot 10^{7} \Omega\end{array}$ \\
\hline $\begin{array}{l}\text { ice-like water } \\
\text { layers }\end{array}$ & $\begin{array}{c}\text { impact on the signal at } \\
\text { isothermal conditions }(R T) \text { : } \\
\mathrm{p}<1 \text { mbar }\end{array}$ & $\begin{array}{c}<1 \% \text { relative humidity, } \\
\text { starting conditions of } \\
\text { moisture sorption }\end{array}$ & $\begin{array}{c}\text { removal/uptake isobaric } \\
\text { conditions: } \\
380-500 \mathrm{~K}\end{array}$ \\
\hline
\end{tabular}




\begin{tabular}{|c|c|c|c|}
\hline & $\begin{array}{c}\text { removal/uptake isobaric } \\
\text { conditions: } \\
333 \mathrm{~K}<\mathrm{T}<500 \mathrm{~K}\end{array}$ & measurement & \\
\hline $\begin{array}{c}\text { reversible } \\
\text { chemisorption/ } \\
\text { OH groups }\end{array}$ & $\begin{array}{c}\text { impact on the signal at } \\
\text { isothermal conditions: } \\
\mathrm{p}<10^{-3} \mathrm{mbar} \\
\text { removal/uptake isobaric } \\
\text { conditions: } \\
500 \mathrm{~K}<\mathrm{T}<900 \mathrm{~K}\end{array}$ & - & $\begin{array}{l}\text { Removal/uptake isobaric } \\
\text { conditions: } \\
500-900 \mathrm{~K} \\
\text { increased amount after re- } \\
\text { cooling } \rightarrow \text { decreased } \\
\text { impedance value, } \\
\text { Nyquist plot after re- } \\
\text { cooling via enhanced } \\
\text { protonic conduction }\end{array}$ \\
\hline
\end{tabular}

The temperature-related conduction mechanisms of the YSZ pellet in moist atmosphere can be summarized as follows: up to $\sim 450 \mathrm{~K}$ decreasing impact of the proton conduction and up to $750 \mathrm{~K}$ hydroxyl-mediated oxide-ion transfer at the grain boundaries with a stable $\mathrm{OH}$ density on the surface. Above $750 \mathrm{~K}$ a transient zone with progressive dehydroxylation is suggested, where hydroxyl-mediated and pure $\mathrm{O}^{2-}$ conduction at grain boundaries is present and at even higher temperature, only the pure $\mathrm{O}^{2-}$ conduction is dominant in the bulk as well as at the grain boundaries. This is also in good agreement with a study conducted by Scherrer et al. ${ }^{36}$ who also postulated these three temperature regions with different conduction mechanisms that can be distinguished on YSZ.

For direct comparison to YSZ, Figures 6A-D (pink and light green traces) show the corresponding impedance measurements on $\mathrm{ZrO}_{2}$. Only two distinct temperature regions are visible in all four measurements: the first one is between $\mathrm{RT}$ and $\sim 600 \mathrm{~K}$ in $\mathrm{H}_{2} \mathrm{O}$ (RT and $\sim 700 \mathrm{~K}$ in $\mathrm{D}_{2} \mathrm{O}$ ) and the second one at $\mathrm{T}>600 \mathrm{~K}$ for treatment in $\mathrm{H}_{2} \mathrm{O}$ and $\mathrm{T}>700 \mathrm{~K}$ for $\mathrm{D}_{2} \mathrm{O}$. The first temperature region is a plateau-like region in the $\mathrm{G} \Omega$ range (detection limit of EIS spectrometer) where the sample shows perfectly insulating properties, and in the second one the sample exhibits semiconductive properties (final value of $\sim 5 \cdot 10^{5} \Omega$ at $1173 \mathrm{~K}$ on all four samples). Upon re-cooling, exactly the same trend as for the heating routine is apparent and there are hardly any differences in the impedance course. In all four gas atmospheres and partial pressures there is no decreased impedance between $\mathrm{RT}$ and $350 \mathrm{~K}$ on $\mathrm{ZrO}_{2}$, as seen on 
the other oxides. Thus, the equivalent layers of physisorbed water (with respect to ice-like/ polymeric chained layer capacity) on this oxide - matching the findings of FT-IR and sorption measurements - do not contribute to the overall impedance/conductivity of the sample at all. As derived from the discussion of Figure 5 in section 3.3, the almost doubled amount of adsorbed water on YSZ in the complete ice-like state (prior to the sorption of polymeric chained water) can be in part assigned to the substantial coverage with dissociated/ chemisorbed water species. In essence, the predominantly molecular/physisorbed ice-like water layer and also the following layers on the strongly and irreversibly de-hydroxylated pure monoclinic $\mathrm{ZrO}_{2}$ exhibit no measurable protonic conductivity. This result is consistent with the absence of the proton hopping mechanism proposed by Raz et al. ${ }^{13}$ for YSZ, which is inherently linked to the presence of a sufficient density of hydroxyl groups on $\mathrm{ZrO}_{2}$ from water dissociation. In this view, the absence of protonic conduction can be regarded as a clear proof for the inability of high-temperature annealed monoclinic $\mathrm{ZrO}_{2}$ surfaces to dissociate a relevant amount of water in the whole experimental temperature range. Obviously, both conduction mechanisms proposed by $\mathrm{Raz}^{13}$ for the chemisorbed and the following ice-like layer are inhibited. Furthermore, the additional polymeric-chained and liquid-like water species are equally insulating up to water condensation at $\sim 24$ mbar. This, moreover, suggests the absence of a fully percolated water film between the grains only on $\mathrm{ZrO}_{2}$. All these results set pure monoclinic $\mathrm{ZrO}_{2}$ very much apart from the more surface-reactive $\mathrm{YSZ}$ and $\mathrm{Y}_{2} \mathrm{O}_{3} .{ }^{16}$ Figure S7 shows the comparison of the temperature dependent evaluation of the FT-IR data of YSZ and $\mathrm{ZrO}_{2}$ in 24 mbar $\mathrm{H}_{2} \mathrm{O}$ at $3160 \mathrm{~cm}^{-1}$. As already mentioned, this wavenumber represents a binding state of water molecules or $\mathrm{OH}$ groups that are interconnected. Due to the high amount of $\mathrm{OH}$-groups on YSZ also the chemisorbed $\mathrm{OH}$ species do contribute to this signal (saved in the background and thus, "negative" values are possible for YSZ). In contrast, on $\mathrm{ZrO}_{2}$ the few chemisorbed $\mathrm{OH}$ species are far away of each other and do not contribute to this signal and are not evaluated in this plot. In fact, in Figure $\mathrm{S} 7$ for $\mathrm{ZrO}_{2}$ the pure 
contribution of polymeric chained and ice-like water is displayed, which is perfectly correlated with the model calculation in Figure S4.

When exposing the (most easily and deeply hydrolysable) $\mathrm{Y}_{2} \mathrm{O}_{3}$ sample to 24 mbar $\mathrm{H}_{2} \mathrm{O}$ and $\mathrm{D}_{2} \mathrm{O}$ and restricting the heating up to around $1173 \mathrm{~K}$ (Figure $6 \mathrm{~A}$ and $\mathrm{C}$ yellow and light blue traces) basically three temperature regions in the temperature-dependent impedance spectra can be distinguished: the first one between $\mathrm{RT}$ and $\sim 350 \mathrm{~K}$ where the liquid-like water layers contribute strongly, the second from $350 \mathrm{~K}$ up to $\sim 600 \mathrm{~K}$ with a plateau-like impedance behavior, and the third one at $\mathrm{T}>600 \mathrm{~K}$, exhibiting semiconductive behavior. At the maximum temperature an impedance value of $\sim 3 \cdot 10^{5} \Omega$ at $1173 \mathrm{~K}$ is obtained (note that the value for YSZ at this temperature is 3 magnitudes lower due to its high oxide ion conductivity). In Figure 6A differences in the heating and cooling procedures are apparent between $508-906 \mathrm{~K}$. This discrepancy is due to the fact that during the heating and cooling routine even more $\mathrm{OH}$-groups are generated - i.e. the proceeding hydrolysis of the $\mathrm{Y}_{2} \mathrm{O}_{3}$ surface near regions leads to a gradually improved conductivity. Upon re-cooling to RT a very similar trend as in the beginning of the experiment is observed: the impedance starts to decrease again due to physisorbed water layers with a final value of $4 \cdot 10^{6} \Omega$ at RT. This is comparable to the value obtained for the plateau at $\sim 333 \mathrm{~K}$ for YSZ with $\sim 1 \cdot 10^{6} \Omega$. Upon treatment of $\mathrm{Y}_{2} \mathrm{O}_{3}$ in 24 mbar $\mathrm{D}_{2} \mathrm{O}$ (Figure 6C), again, differences in the heating and cooling procedures are apparent between $573-973 \mathrm{~K}$, but they are not as pronounced as during treatment in 24 mbar $\mathrm{H}_{2} \mathrm{O}$. Upon re-cooling at $573 \mathrm{~K}$ the impedance is in the $\mathrm{G} \Omega$ area, until at $\mathrm{T}<330 \mathrm{~K}$ it starts to decrease again leading to a value of $\sim 2 \cdot 10^{6} \Omega$ at $\mathrm{RT}$. The fact that the condensed water film exhibits conductivity values close to those of pure water ${ }^{35}$ indicates that full percolation of this film is attained, most likely because of more efficient, hydroxylationinduced surface wetting, in strong contrast to pure $\mathrm{ZrO}_{2}$. Vice versa, the ice-like and polymeric chained water layers on $\mathrm{Y}_{2} \mathrm{O}_{3}$ are equally insulating as on $\mathrm{ZrO}_{2}$, meaning that the above-discussed proton hopping mechanism is absent. A possible explanation comes from the 
high basicity of $\mathrm{Y}_{2} \mathrm{O}_{3}$ (rather associated with $\mathrm{OH}^{-}$anionic species) as compared to YSZ, where comparably acidic $\mathrm{Zr}-\mathrm{OH}$ entities are present.

If the $\mathrm{Y}_{2} \mathrm{O}_{3}$ samples that are treated in 4 mbar $\mathrm{H}_{2} \mathrm{O}$ and $\mathrm{D}_{2} \mathrm{O}$ (Figure $6 \mathrm{~B}$ and $\mathrm{D}$ yellow and light blue traces) are compared to each other, an almost identical impedance course is observed for the heating and cooling curves. No measurable impact of proton conduction in physisorbed water layers below the condensation limit occurs (like it was the case for 24 mbar). This shows again that only a fully percolated water film with its intrinsic conductivity can explain the high RT/ 24 mbar conductivity on $\mathrm{Y}_{2} \mathrm{O}_{3}$.

To sum up, pronounced differences between the three samples, being strongly dependent on the different gas treatments and partial pressures, wre observed. In general, YSZ shows the highest conductivity (lowest impedance) which is due to its high oxide ion conduction at high temperatures. $\mathrm{Y}_{2} \mathrm{O}_{3}$ and $\mathrm{ZrO}_{2}$ show impedance values that are about three magnitudes higher than the ones obtained for YSZ at $1173 \mathrm{~K}$. Depending on the $\mathrm{H}_{2} \mathrm{O} / \mathrm{D}_{2} \mathrm{O}$ partial pressure $(24$ or 4 mbar) and the sample a lower impedance in the temperature range between $\mathrm{RT}-355 \mathrm{~K}$ $\left(\mathrm{Y}_{2} \mathrm{O}_{3}: 24\right.$ mbar $\mathrm{H}_{2} \mathrm{O}$ and $\mathrm{D}_{2} \mathrm{O}$ ) and $\mathrm{RT}-410 \mathrm{~K}$ (YSZ: 4 and 24 mbar $\mathrm{H}_{2} \mathrm{O}$ and $\mathrm{D}_{2} \mathrm{O}$ ) in comparison to dry conditions (Figure 6) is obtained, which is due to the formation and removal of physisorbed water layers. 
Frequency-dependent electrochemical impedance analysis of $\mathrm{YSZ}$ in $\mathrm{H}_{2} \mathrm{O}$ and $\mathrm{D}_{2} \mathrm{O}$
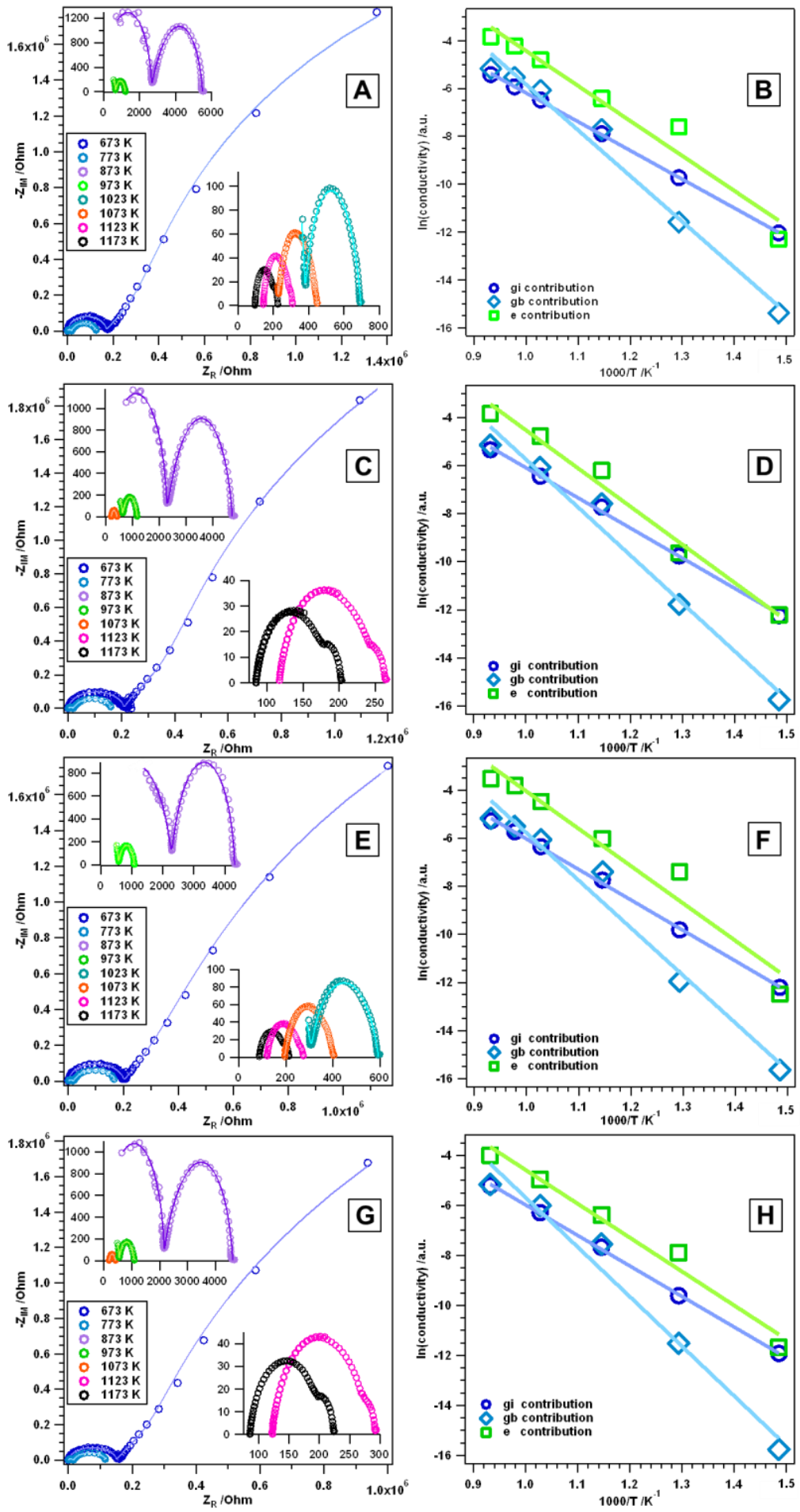

Figure 8: Nyquist plots (data points), simulated spectra (continuous lines) and Arrhenius plots of the grain interior, grain boundary and the electrode contribution of a YSZ powder pellet sample treated in 24 mbar $\mathrm{H}_{2} \mathrm{O}$ (panel A and B), 4 mbar $\mathrm{H}_{2} \mathrm{O}$ (panel C and D), 24 mbar $\mathrm{D}_{2} \mathrm{O}$ (panel $\mathrm{E}$ and $\mathrm{F}$ ) and 4 mbar $\mathrm{D}_{2} \mathrm{O}$ (panel $\mathrm{G}$ and $\mathrm{H}$ ) (flow $\sim 1.0 \mathrm{~mL} \mathrm{~s}^{-1}$ ) at selected 
temperatures between RT and $1173 \mathrm{~K}$. The lowest frequency of $0.1 \mathrm{~Hz}$ is at the right side and the highest one of $0.1 \mathrm{MHz}$ at the left side of the $\mathrm{x}$-axis in the NP's. The insets in panels A, C, E and $\mathrm{G}$ show zoomed regions of the NPs at higher temperatures.

Figure 8 highlights the corresponding Nyquist plots (NP's) of the YSZ sample treated in different gas pressures (4 and 24 mbar) of $\mathrm{H}_{2} \mathrm{O}$ and $\mathrm{D}_{2} \mathrm{O}$ in flowing $\mathrm{He}$ at different temperatures. At $673 \mathrm{~K}$, a frequency-dependent impedance plot with two "semicircles" is apparent with a small one at high frequencies (HF) and a very big one at low frequencies (LF). Note that in the chosen frequency range of $0.1 \mathrm{~Hz}-0.1 \mathrm{MHz}$ this low frequency semicircle is not completely pictured in the frequency dependent impedance spectra. At $\mathrm{T} \geq$ $773 \mathrm{~K}$ two well-defined semicircles are visible: a very large one at high frequencies (HF) and a smaller one at low frequencies (LF) with "tailing". If the system is heated up to $873 \mathrm{~K} \mathrm{a}$ different trend becomes apparent: the maximum of the two arcs and, hence, the resistance of these two processes is very similar. It is already known from literature ${ }^{18,19}$, that in this temperature region the surface conductivity phenomena become increasingly dominated by bulk ion conductivity. The higher the temperature gets, the less influence surface chemistry has on the conductivity and hence, on the frequency dependent impedance experiments.

At temperatures of $923 \mathrm{~K}$ and beyond, the relative resistivity contributions of the two arcs change again, resulting in a dominant first arc at high frequencies. If the system is heated up to even higher temperatures (see insets in the upper right corner, Figure 8A, C, E, G), another trend becomes clear: starting at $\mathrm{T} \geq 873 \mathrm{~K}$, the HF semicircle of the NP is getting less and less pronounced in the chosen frequency range, which also makes it difficult to exactly determine the maximum intensity of this contribution with respect to the resistance and capacitance. At a temperature of $1073 \mathrm{~K}$ only a few data points of the first semicircle are present and at $1123 \mathrm{~K}$ basically no contribution of the first semicircle is visible (note that this does not indicate that this contribution is not present anymore - as mentioned before it is simply not detectable 
within the chosen frequency range). Due to the lack of data points for the HF Nyquist plot at $1123 \mathrm{~K}$ and $1173 \mathrm{~K}$, no fit could be applied. As shown in Figure 8A and E, basically the same trends apply to the different measurements, although conducted in different gas atmospheres.

A general trend for all gas treatments in Figure 8 can be observed: both the HF and LF contributions (this will be later related to grain interior gi and gb contribution) significantly decrease during the measurement whilst heating the system to higher temperatures. Thus, the higher the temperature, the lower the contribution of these parameters is. The numerical values of the respective capacitive and resistive parameters at the chosen temperatures are also shown in Table S3 - S6.

Many attempts have been made to find the most representative, but at the same time also most simple, equivalent circuit model for a powder-based ionic conductor such as YSZ..$^{37-54}$ However, this is not an easy task, because - in contrast to single crystal YSZ samples additional parameters have to be taken into account, in particular grain size and grain boundary effects. ${ }^{39,40,48,49,52,55,56}$ As the semicircles are often a complex superposition of the distinct involved processes, the complete and unambiguous disentanglement of the resistivity and capacitance contributions becomes difficult. ${ }^{47,}{ }^{49}$ Nevertheless, sufficiently reliable fit models (originally by Bäuerle et al. $^{26}$ ) have already been established and their validity proven. ${ }^{19,38}$ From a previous study ${ }^{19}$ and literature data, ${ }^{49,54}$ it is already known that the grain interior (bulk) contribution is usually observed at high frequencies, whereas grain boundary and electrode contributions are located at mid and lower frequency part of the Nyquist plot, respectively. The "tailing" of the arc in the low frequency range is due to interaction between the electrode and the sample pellet. ${ }^{19,49,54}$ This described "tailing" is actually the onset of another semicircle which is, as mentioned before, due to electrode interface contribution and is usually more pronounced at higher temperature.

The circuit that we used in this study to fit the experimental data is composed of constant phase elements (CPE's) instead of ideal (Debye) capacitors (Figure 9). This is common for 
polycrystalline samples due to material inhomogeneity, surface defects such as pores, electrode roughness and ionic transport deviation from Fick's law, giving rise to a certain degree of frequency dispersion and non-uniformity of the current density. Hence, these elements more accurately represent the capacitive behavior of this kind of cell in the whole studied frequency range (which can also be clearly seen in the depressed semicircles). ${ }^{53,57,58}$ Using the equivalent circuit model, the capacitances (C) were calculated using the formula

$$
C=\left(R^{1-\alpha} \cdot Q\right)^{1 / \alpha}
$$

with $Q$ being the value obtained for the respective $\mathrm{CPE}$ and $\alpha$ indicating whether the $\mathrm{CPE}$ behaves more like an ideal capacitor $(\alpha=1)$ or more like an ideal resistance $(\alpha=0)$.

The parameters of the equivalent circuit model used to fit the experimental data are summarized in Tables S3 - S6. The basic agreement of the simulated spectra with the experimental data supports the general validity of the equivalent circuit diagram and also the comparison to other studies on similar materials and under comparable conditions. The comparison of the experimental values for the different contributions to other works in

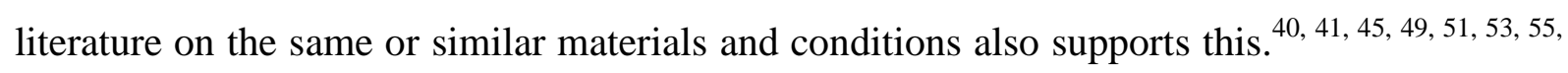
$59-65$

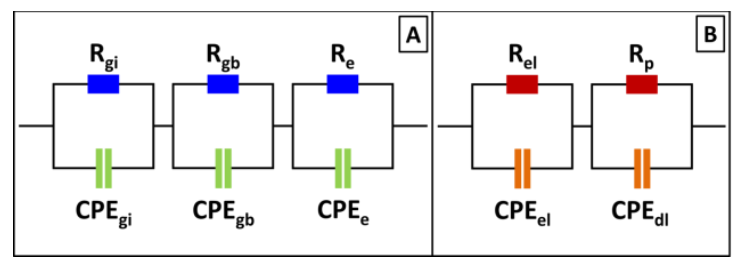

Figure 9: Equivalent circuit model used for fitting the frequency-dependent impedance data of the samples represented in Figure 9 (A) between 673 - $1073 \mathrm{~K}$ with contributions from the grain interiors (gi), grain boundaries (gb) and electrode (e) without liquid-like water film; (B) fit model for the NP's during treatment in 24 mbar $\mathrm{H}_{2} \mathrm{O} / \mathrm{D}_{2} \mathrm{O}$ after re-cooling to RT with contributions from the electrolyte (el) and chemical polarization (p) of the electrode and double layer (dl) with fully percolated liquid-like water film (for the discussion of Figure S9). 
With the equivalent circuit (Figure 9A) it is now possible to distinguish the different contributions for the different processes (gi, gb and e). With this information, the temperature dependency of these contributions in the different gas atmospheres and under different partial pressures could be elucidated (Tables S3 - S6). One of the trends that all measurements have in common is that the higher the temperature, the lower the impedance contributions are, converging to a final value. At the lower temperatures (673 and $773 \mathrm{~K}$ ) the grain boundary contribution is for all experiments one magnitude lower than the one from the grain interiors. Starting at $\mathrm{T}>773 \mathrm{~K}$ this ratio changes and the contributions are comparable. At least with respect to the impedance behavior without extended liquid-like water layers, there are basically only small differences between the different moist gas treatments at 4 and 24 mbar $\mathrm{H}_{2} \mathrm{O} / \mathrm{D}_{2} \mathrm{O}$.

If the values in Table S3 - S6 are compared to the ones found in literature, again differences/similarities can be outlined. Similar $\mathrm{C}_{\mathrm{gi}}$ values as ours have been found by e.g. Lacroix et al. $\left(\mathrm{SrZr}_{0.9} \operatorname{Ln}_{0.1} \mathrm{O}_{2.95}\right){ }^{45}$ For the grain boundary capacitance, 8 -ScSZ ${ }^{66}$ shows a similar clear trend: the higher the temperature (maximum $723 \mathrm{~K}$ ) the higher the value for the grain boundary capacitance. $\mathrm{A} \mathrm{C}_{\mathrm{gb}}$ value of $1.71 \cdot 10^{-6} \mathrm{~F}$ at $723 \mathrm{~K}$ was reported. Verkerk et al. ${ }^{48}$ also studied the impact of grain size on the $\mathrm{C}_{\mathrm{gb}}$. He found a value of $\sim 3.0 \cdot 10^{-6} \mathrm{~F}$ at $673 \mathrm{~K}$ for an alkoxide sample $\left[\left(\mathrm{ZrO}_{2}\right)_{1-\mathrm{x}}\left(\mathrm{YO}_{1.5}\right)_{\mathrm{x}} ; \mathrm{x}=0.164\right]$ with a grain size of $\sim 13 \mu \mathrm{m}$ and also $~$ $3.0 \cdot 10^{-6} \mathrm{~F}$ at $673 \mathrm{~K}$ for a Zircar sample $\left[\left(\mathrm{ZrO}_{2}\right)_{1-\mathrm{x}}\left(\mathrm{YO}_{1.5}\right)_{\mathrm{x}} ; \mathrm{x}=0.140\right]$ with a grain size of $\sim$ $11 \mu \mathrm{m}$. It has already been stated in literature ${ }^{54}$ that there are two temperature regimes for a $\mathrm{Pt}|\mathrm{YSZ}| \mathrm{Pt}$ cell such as the one that we used: a low temperature region up to $720 \mathrm{~K}$ where the Pt electrode behaves as blocked and the capacitance assumes values between $10^{-12}-10^{-10}$ F (note that grain boundary capacitance values of Nyquist plots at the lowest temperature of $673 \mathrm{~K}$ fit quite well with this) and a high temperature region ( $\mathrm{T}>720 \mathrm{~K}$ ) with capacitances up to $10^{-3} \mathrm{~F}$. The grain boundary capacitance values of the Nyquist plot at $673 \mathrm{~K}$ for all 4 different gas treatments and pressures fits very well with the values in the low temperature 
region. However, the ones that we obtained at $\mathrm{T}>720 \mathrm{~K}$ are much lower than the ones stated by Wierzbicka et al. ${ }^{54}$ (discrepancies of $\sim 3 / 4$ magnitudes).

Using the obtained resistance values for $\mathrm{R}_{\mathrm{gi}}, \mathrm{R}_{\mathrm{gb}}$ and $\mathrm{R}_{\mathrm{e}}$, an Arrhenius plot of $\ln$ (conductivity) of the respective contribution vs. the reciprocal of the temperature in the temperature region between 673 - $1073 \mathrm{~K}$ (Figure 8B, D, F, H) yields the "apparent" activation energies for the different contributions. For detailed numerical values see Table S7. An average value of $1,06 \mathrm{eV}\left(110 \mathrm{kJmol}^{-1}\right)$ for all 4 gas treatments is obtained for the grain interior process, perfectly fitting to the activation energy for bulk anion conductivity in YSZ. ${ }^{38}$ In contrast, the highest activation energy value of $\sim 1.69 \mathrm{eV}\left(175 \mathrm{kJmol}^{-1}\right)$ of all three processes is obtained for the grain boundary contribution. In general, the values for $E_{A}(g i)$ and $E_{A}(g b)$ show a very similar temperature trend and are hardly distinguishable with respect to the water pressure. In contrast to this result, the activation energies for the electrode process differ to some extent, depending on the used $\mathrm{H}_{2} \mathrm{O} / \mathrm{D}_{2} \mathrm{O}$ treatment/partial pressure (Tables $\mathrm{S} 3$ - S6). If the obtained values for $\mathrm{E}_{\mathrm{A}}(\mathrm{gi})$ and $\mathrm{E}_{\mathrm{A}}(\mathrm{gb})$ in this work are compared with the ones found in literature, ${ }^{36,38 \text {, }}$ $42,52-54,56,60,63,65,67,68$ some of the experimental data agree quite well with the values from this work - especially the values obtained for $\mathrm{E}_{\mathrm{A}}(\mathrm{gi})$. Concerning the activation energy for the grain boundaries, different $\mathrm{E}_{\mathrm{A}}$ 's can be extracted from literature, most of them being lower than the values that we calculated. However, there are some reports of higher activation energies for this process that are very similar to ours, especially the one that Gong et. al. ${ }^{65}$ obtained. These differences in the obtained $\mathrm{E}_{\mathrm{A}}$ 's can be easily explained in terms of different pre-treatments of the samples, gas atmospheres and different experimental conditions e.g. moist or dry conditions, different heating rates, different temperature regions used for the linear fits. However, comparable values for $\mathrm{E}_{\mathrm{A}}(\mathrm{e})$ could not be found due to the lack of literature data. 


\section{Conclusions}

The combined study of water adsorption on the ceramic oxides $\mathrm{YSZ}, \mathrm{ZrO}_{2}$ and $\mathrm{Y}_{2} \mathrm{O}_{3}$ using operando FT-IR spectroscopy, operando electrochemical impedance spectroscopy and dynamic moisture sorption measurements allowed to experimentally verify a pressure- and temperature-dependent layer-by-layer adsorption model with clearly distinguishable states of (1) chemisorbed $\mathrm{OH}$ groups at low pressures and high temperatures, acting as "anchors" as well as proton-donors for the gradually more and more weakly bonded (2) ice-like, (3) polymeric chained and (4) liquid-like molecular water layers. The absence of the reversibly populated chemisorbed water species on pure monoclinic $\mathrm{ZrO}_{2}$ could be verified and directly related to the absent protonic conductivity of the respective water films. Concerning the distinct adsorption energetics, binding strengths and conduction properties observed with increasing water coverages, well-correlated data in the pressure range from $10^{-5}$ mbar up to ambient pressure and the temperature range between $1173 \mathrm{~K}$ and RT were obtained, bridging the gap between low-temperature (U)HV and high-temperature ambient pressure investigations. It was possible to assign basically all discrete signals/regions in the infrared spectra to the different water binding states. From the related EIS investigations on YSZ, the temperature- and pressure-related stability and protonic conductivity of the water layers/ adsorbed states could be quantified. Independently from the low-temperature water surface chemistry, activation energies and the anionic resistivity contributions of grain interior, grain boundary and the electrode could be quantified in the presence of water vapor up to $1173 \mathrm{~K}$. A perfect correlation of the temperature dependent impedance course and the related water adsorption stages with the infrared data obtained under identical experimental conditions clarifies the impact of water/OH-groups on YSZ at close to SOFC relevant conditions (temperatures up to $1173 \mathrm{~K}$, ambient pressure). The specific impact of water on the YSZbased anode- and electrolyte surfaces and -interfaces can, thus, be considered as a basis of further application-oriented investigations of the oxides in other gases mixed with water 
vapor, since under realistic high-pressure and high-temperature conditions of relevant fuel gas and/or reforming mixtures a certain amount of dissociated water and dynamic surface hydroxylation is most likely always present.

Finally, with regard to low-temperature catalytic reforming processes occurring already around $500 \mathrm{~K}$ (e.g. methanol steam reforming), the relative population and the specific reactivities of the ice-like molecular and dissociated water species could be provided in order to correctly assess the potential co-catalytic function of $\mathrm{ZrO}_{2}$-based oxidic support materials for efficient water activation. In this view, it appears highly interesting to study the consequences of the strongly different water chemisorption properties of e.g. YSZ and pure $\mathrm{ZrO}_{2}$ polymorphs with respect to reforming activity and selectivity.

\section{Acknowledgments}

We thank the FWF (Austrian Science Foundation) for financial support under the project F4503-N16 of the SFB "Functional Oxide Surfaces and Interfaces" (FOXSI). The work has been performed within the framework of the research platform "materials and nanoscience" at the University of Innsbruck.

Supporting Information provides additional FT-IR experiments and impedance measurements, as well as additional Tables with parameters of the impedance peak fitting routines.

\section{References}

(1) Schlögl, R., Heterogeneous Catalysis. Angew. Chem. Int. Edit. 2015, 54 (11), 34653520.

(2) Daniells, S. T.; Overweg, A. R.; Makkee, M.; Moulijn, J. A., The Mechanism of LowTemperature CO Oxidation with $\mathrm{Au} / \mathrm{Fe}_{2} \mathrm{O}_{3}$ Catalysts: A Combined Mössbauer, FT-IR, and TAP Reactor Study. J. Catal. 2005, 230 (1), 52-65. 
(3) Zhang, Z.; Du, Y.; Petrik, N. G.; Kimmel, G. A.; Lyubinetsky, I.; Dohnalek, Z., Water as a Catalyst: Imaging Reactions of $\mathrm{O}_{2}$ with Partially and Fully Hydroxylated $\mathrm{TiO}_{2}(110)$ Surfaces. J. Phys. Chem. C 2009, 113 (5), 1908-1916.

(4) Moreau, F.; Bond, G. C.; van der Linden, B.; Silberova, B. A. A.; Makkee, M., Gold Supported on Mixed Oxides for the Oxidation of Carbon Monoxide. Appl. Catal. A 2008, 347 (2), 208-215.

(5) Leist, U.; Ranke, W.; Al-Shamery, K., Water Adsorption and Growth of Ice on Epitaxial $\mathrm{Fe}_{3} \mathrm{O}_{4}(111), \mathrm{FeO}(111)$ and $\mathrm{Fe}_{2} \mathrm{O}_{3}$ (biphase). Phys. Chem. Chem. Phys. 2003, 5 (11), 2435-2441.

(6) Henderson, M. A., The Interaction of Water with Solid Surfaces: Fundamental Aspects Revisited. Surf. Sci. Rep. 2002, 46 (1-8), 1-308.

(7) Smith, R. J. B.; Loganathan, M.; Shantha, M. S., A Review of the Water Gas Shift Reaction Kinetics. Int. J. Chem. Reac. Eng. 2010, 8, 34.

(8) Caporali, R.; Chansai, S.; Burch, R.; Delgado, J. J.; Goguet, A.; Hardacre, C.; Mantarosie, L.; Thompsett, D., Critical Role of Water in the Direct Oxidation of CO and Hydrocarbons in Diesel Exhaust After Treatment Catalysis. Appl. Catal. B 2014, 147, 764-769.

(9) Royer, S.; Duprez, D., Catalytic Oxidation of Carbon Monoxide over Transition Metal Oxides. ChemCatChem 2011, 3 (1), 24-65.

(10) Li, S. Y.; Jia, M. J.; Gao, J.; Wu, P.; Yang, M. L.; Huang, S. H.; Dou, X. W.; Yang, Y.; Zhang, W. X., Infrared Studies of the Promoting Role of Water on the Reactivity of $\mathrm{Pt} / \mathrm{FeOx}$ Catalyst in Low-Temperature Oxidation of Carbon Monoxide. J. Phys. Chem. C 2015, 119 (5), 2483-2490.

(11) Sa, S.; Silva, H.; Brandao, L.; Sousa, J. M.; Mendes, A., Catalysts for Methanol Steam Reforming-A Review. Appl. Catal. B 2010, 99 (1-2), 43-57. 
(12) Achenbach, E.; Riensche, E., Methane Steam Reforming Kinetics for Solid Oxide Fuel Cells. J. Power Sources 1994, 52 (2), 283-288.

(13) Raz, S.; Sasaki, K.; Maier, J.; Riess, I., Characterization of Adsorbed Water Layers on $\mathrm{Y}_{2} \mathrm{O}_{3}$-doped $\mathrm{ZrO}_{2}$. Solid State Ionics 2001, 143 (2), 181-204.

(14) Kogler, M.; Köck, E. M.; Bielz, T.; Pfaller, K.; Klötzer, B.; Schmidmair, D.; Perfler, L.; Penner, S., Hydrogen Surface Reactions and Adsorption Studied on $\mathrm{Y}_{2} \mathrm{O}_{3}$, YSZ, and $\mathrm{ZrO}_{2}$. J. Phys. Chem. C 2014, 118 (16), 8435-8444.

(15) Mukhopadhyay, M.; Mukhopadhyay, J.; Basu, R. N., Functional Anode Materials for Solid Oxide Fuel Cell - A Review. T. Indian Ceram. Soc. 2013, 72 (3), 145-168.

(16) Köck, E. M.; Kogler, M.; Bielz, T.; Klötzer, B.; Penner, S., In Situ FT-IR Spectroscopic Study of $\mathrm{CO}_{2}$ and $\mathrm{CO}$ Adsorption on $\mathrm{Y}_{2} \mathrm{O}_{3}, \mathrm{ZrO}_{2}$, and Yttria-Stabilized $\mathrm{ZrO}_{2}$. J. Phys. Chem. C 2013, 117 (34), 17666-17673.

(17) Kogler, M.; Köck, E. M.; Perfler, L.; Bielz, T.; Stöger-Pollach, M.; Hetaba, W.; Willinger, M.; Huang, X.; Schuster, M.; Klötzer, B.; Penner, S., Methane Decomposition and Carbon Growth on $\mathrm{Y}_{2} \mathrm{O}_{3}, \mathrm{ZrO}_{2}$, and Yttria-Stabilized $\mathrm{ZrO}_{2}$. Chem. Mater. 2014, 26 (4), 1690-1701.

(18) Kogler, M.; Köck, E. M.; Klötzer, B.; Schachinger, T.; Wallisch, W.; Henn, R.; Huck, C. W.; Hejny, C.; Penner, S., High-Temperature Carbon Deposition on Oxide Surfaces by CO Disproportionation. J. Phys. Chem. C 2016, 120 (3), 1795-1807.

(19) Kogler, M.; Köck, E.-M.; Klötzer, B.; Perfler, L.; Simon, P., Surface Reactivity of YSZ, $\mathrm{Y}_{2} \mathrm{O}_{3}$, and $\mathrm{ZrO}_{2}$ toward $\mathrm{CO}, \mathrm{CO}_{2}$, and $\mathrm{CH}_{4}$ : A Comparative Discussion. J. Phys. Chem. C 2016, 120 (7), 3882-3898.

(20) Köck, E.-M.; Kogler, M.; Pramsoler, R.; Klötzer, B.; Penner, S., A High-Temperature , Ambient-Pressure Ultra-Dry Operando Reactor Cell for Fourier-Transform Infrared Spectroscopy. Rev. Sci. Instrum. 2014, 85 (8), 084102. 
(21) Wagner, W.; Riethmann, T.; Feistel, R.; Harvey, A. H., New Equations for the Sublimation Pressure and Melting Pressure of $\mathrm{H}_{2} \mathrm{O}$ Ice Ih. J. Phys. Chem. Ref. Data 2011, 40 (4), 11.

(22) Thiel, P. A.; Madey, T. E., The Interaction of Water With Solid Surfaces - Fundamental Aspects. Surf. Sci. Rep. 1987, 7 (6-8), 211-385.

(23) Kouva, S.; Honkala, K.; Lefferts, L.; Kanervo, J., Review: Monoclinic Zirconia, its Surface Sites and Their Interaction With Carbon Monoxide. Catal. Sci.Technol. 2015, 5 (7), 3473-3490.

(24) Takeuchi, M.; Martra, G.; Coluccia, S.; Anpo, M., Investigations of the Structure of $\mathrm{H}_{2} \mathrm{O}$ Clusters Adsorbed on $\mathrm{TiO}_{2}$ Surfaces by Near-Infrared Absorption Spectroscopy. $J$. Phys. Chem. B 2005, 109 (15), 7387-7391.

(25) He, M. Y.; Ekerdt, J. G., Infrared Studies of the Adsorption of Synthesis Gas on Zirconium Dioxide. J. Catal. 1984, 87 (2), 381-388.

(26) Bianchi, D.; Gass, J. L.; Khalfallah, M.; Teichner, S. J., Intermediate Species on Zirconia Supported Methanol Aerogel Catalysts. 1. State of the Catalyst Surface before and after the Adsorption of Hydrogen. Appl. Catal. A 1993, 101 (2), 297-315.

(27) Bachiller-Baeza, B.; Rodriguez-Ramos, I.; Guerrero-Ruiz, A., Interaction of Carbon Dioxide with the Surface of Zirconia Polymorphs. Langmuir 1998, 14 (13), 3556-3564.

(28) Kouva, S.; Andersin, J.; Honkala, K.; Lehtonen, J.; Lefferts, L.; Kanervo, J., Water and Carbon Oxides on Monoclinic Zirconia: Experimental and Computational Insights. Phys. Chem. Chem. Phys. 2014, 16 (38), 20650-20664.

(29) Ferretto, L.; Glisenti, A., Study of the Surface Acidity of an Hematite Powder. J. Mol. Catal. A. 2002, 187 (1), 119-128.

(30) Si, R. R.; Liu, J. F.; Yang, K.; Chen, X.; Dai, W. X.; Fu, X. Z., Temperature-programed Surface Reaction Study of CO Oxidation over $\mathrm{Au} / \mathrm{TiO}_{2}$ at Low Temperature: An Insight into Nature of the Reaction Process. J. Catal. 2014, 311, 71-79. 
(31) Busing, W. R.; Morgan, H. W., Infrared Spectrum of $\mathrm{Ca}(\mathrm{OH})_{2}$. J. Chem. Phys. 1958, 28 (5), 998-999.

(32) Tennyson, J.; Bernath, P. F.; Brown, L. R.; Campargue, A.; Csaszar, A. G.; Daumont, L.; Gamache, R. R.; Hodges, J. T.; Naumenko, O. V.; Polyansky, O. L.; Rothman, L. S.; Vandaele, A. C.; Zobov, N. F.; Al Derzi, A. R.; Fabri, C.; Fazliev, A. Z.; Furtenbacher, T.; Gordon, I. E.; Lodi, L.; Mizus, II, IUPAC Critical Evaluation of the RotationalVibrational Spectra of Water Vapor, Part III: Energy Levels and Transition Wavenumbers for $\left(\mathrm{H}_{2} \mathrm{O}\right)-\mathrm{O}-16$. J. Quant. Spectrosc. Ra. 2013, 117, 29-58.

(33) Sing, K. S. W.; Everett, D. H.; Haul, R. A. W.; Moscou, L.; Pierotti, R. A.; Rouquerol, J.; Siemieniewska, T., Reporting Physisorption Data for Gas Solid Systems With Special Reference to the Determination of Surface Area and Porosity (Recommendations 1984). Pure Appl. Chem. 1985, 57 (4), 603-619.

(34) Sato, R.; Ohkuma, S.; Shibuta, Y.; Shimojo, F.; Yamaguchi, S., Proton Migration on Hydrated Surface of Cubic $\mathrm{ZrO}_{2}$ : Ab initio Molecular Dynamics Simulation. J. Phys. Chem. C 2015, 119, 28925-28933.

(35) Light, T. S.; Licht, S.; Bevilacqua, A. C.; Morash, K. R., The Fundamental Conductivity and Resistivity of Water. Electrochem. Solid St. 2005, 8 (1), E16-E19.

(36) Scherrer, B.; Schlupp, M. V. F.; Stender, D.; Martynczuk, J.; Grolig, J. G.; Ma, H.; Kocher, P.; Lippert, T.; Prestat, M.; Gauckler, L. J., On Proton Conductivity in Porous and Dense Yttria Stabilized Zirconia at Low Temperature. Adv. Funct. Mater. 2013, 23 (15), 1957-1964.

(37) Bauerle, J. E., Study of Solid Electrolyte Polarization by a Complex Admittance Method. J. Phys. Chem. Solids 1969, 30 (12), 2657-2665.

(38) Guo, X.; Maier, J., Grain Boundary Blocking Effect in Zirconia: A Schottky Barrier Analysis. J. Electrochem. Soc. 2001, 148 (3), E121-E126. 
(39) Avila-Paredes, H. J.; Chen, C.-T.; Wang, S.; De Souza, R. A.; Martin, M.; Munir, Z.; Kim, S., Grain Boundaries in Dense Nanocrystalline Ceria Ceramics: Exclusive Pathways for Proton Conduction at Room Temperature. J. Mater. Chem. 2010, 20 (45), 10110-10112.

(40) Avila-Paredes, H. J.; Zhao, J.; Wang, S.; Pietrowski, M.; De Souza, R. A.; Reinholdt, A.; Munir, Z. A.; Martin, M.; Kim, S., Protonic Conductivity of Nano-Structured YttriaStabilized Zirconia: Dependence on Grain Size. J. Mater. Chem. 2010, 20 (5), 990-994.

(41) Kim, S.; Avila-Paredes, H. J.; Wang, S.; Chen, C.-T.; De Souza, R. A.; Martin, M.; Munir, Z. A., On the Conduction Pathway for Protons in Nanocrystalline YttriaStabilized Zirconia. Phys. Chem. Chem. Phys. 2009, 11 (17), 3035-3038.

(42) Tande, C.; Perez-Coll, D.; Mather, G. C., Surface Proton Conductivity of Dense Nanocrystalline YSZ. J. Mater. Chem. 2012, 22 (22), 11208-11213.

(43) Bouchet, R.; Knauth, P.; Laugier, J. M., Theoretical Analysis of IS of Polycrystalline Materials with Blocking or Conducting Grain Boundaries: From Microcrystals to Nanocrystals. J. Electrochem. Soc. 2003, 150 (7), E348-E354.

(44) Bouchet, R.; Knauth, P.; Laugier, J. M., Theoretical Analysis of the Impedance Spectra of Electroceramics - Part 2: Isotropic Grain Boundaries. J. Electroceram. 2006, 16 (3), 229-238.

(45) Lacroix, O.; Rahmouni, K.; Sirat, A.; Takenouti, H.; Deslouis, C.; Keddam, M.; Sala, B., Electrochemical Studies of Water Insertion and Proton - Ceramic Interaction in Substituted Perovskite $\operatorname{SrZr}(0.9) \operatorname{Ln}(0.1) \mathrm{O}(2.95)$. J. Power Sources 2014, 270, 506-515.

(46) Hwang, J. H.; McLachlan, D. S.; Mason, T. O., Brick Layer Model Analysis of Nanoscale-to-Microscale Cerium Dioxide. J. Electroceram. 1999, 3 (1), 7-16.

(47) Kidner, N. J.; Perry, N. H.; Mason, T. O.; Garboczi, E. J., The Brick Layer Model Revisited: Introducing the Nano-Grain Composite Model. J. Am. Ceram. Soc. 2008, 91 (6), 1733-1746. 
(48) Verkerk, M. J.; Middelhuis, B. J.; Burggraaf, A. J., Effect Of Grain-Boundaries on the Conductivity of High-Purity $\mathrm{ZrO}_{2}-\mathrm{Y}_{2} \mathrm{O}_{3}$ Ceramics. Solid State Ionics 1982, 6 (2), 159170.

(49) Rojo, L.; Ga Mandayo, G.; Castano, E. Thin Film YSZ Solid State Electrolyte Characterization Performed by Electrochemical Impedance Spectroscopy, 9th Spanish Conference on Electron Devices (CDE), Valladolid, SPAIN, 2013 Feb 12-14; Valladolid, SPAIN, 2013; pp 233-236.

(50) Hertz, J. L.; Tuller, H. L., Measurement and Finite Element Modeling of Triple Phase Boundary-Related Current Constriction in YSZ. Solid State Ionics 2007, 178 (13-14), 915-923.

(51) Maeland, D.; Suciu, C.; Waernhus, I.; Hoffmann, A. C., Sintering of 4YSZ $\left(\mathrm{ZrO}_{2}+4\right.$ mol\% $\mathrm{Y}_{2} \mathrm{O}_{3}$ ) Nanoceramics for Solid Oxide Fuel Cells (SOFCs), Their Structure and Ionic Conductivity. J. Eur. Ceram. Soc. 2009, 29 (12), 2537-2547.

(52) Peters, C.; Weber, A.; Butz, B.; Gerthsen, D.; Ivers-Tiffee, E., Grain-Size Effects in YSZ Thin-Film Electrolytes. J. Am. Ceram. Soc. 2009, 92 (9), 2017-2024.

(53) Obal, K.; Pedzich, Z.; Brylewski, T.; Rekas, M., Modification of Yttria-doped Tetragonal Zirconia Polycrystal Ceramics. Int. J. Electrochem. Sc. 2012, 7 (8), 68316845.

(54) Wierzbicka, M.; Pasierb, P.; Rekas, M., $\mathrm{CO}_{2}$ Sensor Studied by Impedance Spectroscopy. Physica B-Condensed Matter 2007, 387 (1-2), 302-312.

(55) Tao, J.; Dong, A.; Wang, J., The Influence of Microstructure and Grain Boundary on the Electrical Properties of Scandia Stabilized Zirconia. Mater. Trans. 2013, 54 (5), 825-832.

(56) Martin, M. C.; Mecartney, M. L., Grain Boundary Ionic Conductivity of Yttrium Stabilized Zirconia as a Function of Silica Content and Grain Size. Solid State Ionics 2003, $161(1-2), 67-79$. 
(57) Vishweswaraiah, S. Non-Destructive Micostructuarl Evaluation of Yttria Stabilized Zirconia, Nickel Aluminides and Thermal Barrier Coatings Using Electrochemical Impedance Spectroscopy. PhD Thesis, University of Central Florida, 2000.

(58) Macdonald, J. R., Impedance Spectroscopy - Theory, Experiment and Applications. Wiley: New York, 1987; p page 191.

(59) Madani, A.; Cheikh-Amdounia, A.; Touati, A.; Labidia, M.; Boussetta, H.; Monty, C., Ionic Conductivity of $4 \mathrm{~mol} \%, 9.5 \mathrm{~mol} \%$ YSZ Nanomaterials and $(9.5 \mathrm{~mol} \%$ YSZ)(0.98)-( $\left.\mathrm{Al}_{2} \mathrm{O}_{3}\right)(0.02)$ Nanocomposites. Sensor. Actuat. B-Chem. 2005, 109 (1), 107-111.

(60) Jung, W.; Hertz, J. L.; Tuller, H. L., Enhanced Ionic Conductivity and Phase MetaStability of Nano-Sized Thin Film Yttria-Doped Zirconia (YDZ). Acta Mater. 2009, 57 (5), 1399-1404.

(61) Araki, W.; Imai, Y.; Adachi, T., Mechanical Stress Effect on Oxygen Ion Mobility in 8 mol\% Yttria-Stabilized Zirconia Electrolyte. J. Eur. Ceram. Soc. 2009, 29 (11), 22752279.

(62) Wang, Z. W.; Cheng, M. J.; Bi, Z. H.; Dong, Y. L.; Zhang, H. M.; Zhang, J.; Feng, Z. C.; Li, C., Structure and Impedance of $\mathrm{ZrO}_{2}$ doped with $\mathrm{Sc}_{2} \mathrm{O}_{3}$ and $\mathrm{CeO}_{2}$. Mater. Lett. 2005, 59 (19-20), 2579-2582.

(63) Badenes, J. A.; Benet, P.; Sorli, S.; Tena, M. A.; Monros, G., Characterisation of Y-PSZ and Pr-doped Y-PSZ Obtained by Unconventional Methods for SOFC Applications. Bol. Soc. Esp. Ceram. V. 2004, 43 (4), 787-791.

(64) Takamura, H.; Takahashi, N., Electrical Conductivity of Dense Nanocrystalline Ceria Under Humidified Atmosphere. Solid State Ionics 2010, 181 (3-4), 100-103.

(65) Gong, J. H.; Li, Y.; Zhang, Z. T.; Tang, Z. L., AC Impedance Study of Zirconia Doped with Yttria and Calcia. J. Am. Ceram. Soc. 2000, 83 (3), 648-650. 
(66) Tao, J. C.; Dong, A. P.; Wang, J., The Influence of Microstructure and Grain Boundary on the Electrical Properties of Scandia Stabilized Zirconia. Mater. Trans. 2013, 54 (5), $825-832$.

(67) Fonseca, F. C.; Muccillo, R., Impedance Spectroscopy Analysis of Percolation in (Yttria-Stabilized Zirconia)-Yttria Ceramic Composites. Solid State Ionics 2004, 166 (12), 157-165.

(68) Miyoshi, S.; Akao, Y.; Kuwata, N.; Kawamura, J.; Oyama, Y.; Yagi, T.; Yamaguchi, S., Water Uptake and Conduction Property of Nano-Grained Yttria-Doped Zirconia Fabricated by Ultra-High Pressure Compaction at Room Temperature. Solid State Ionics 2012, 207, 21-28. 


\section{Table of content}

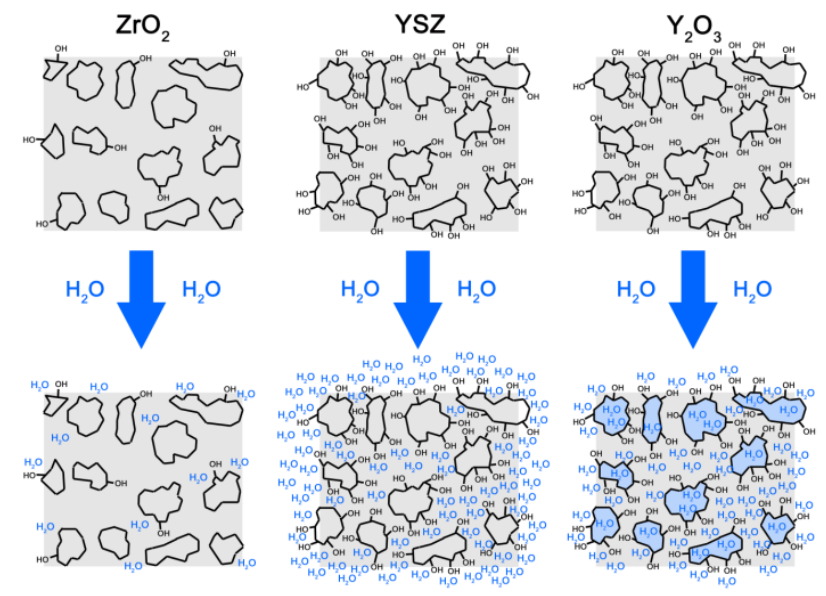

